\title{
Lapurdum
}

Euskal ikerketen aldizkaria | Revue d'études basques |

Revista de estudios vascos | Basque studies review

Numéro Spécial 1 | 1999

Les lettres basques au temps d'Axular (1600-1650)

\section{Les prologues auctoriaux des ouvrages basques des XVIe et XVIIe siècles}

\section{Bernard Oyharçabal}

\section{OpenEdition \\ Journals}

Édition électronique

URL : http://journals.openedition.org/lapurdum/1608

DOI : 10.4000/lapurdum.1608

ISSN : 1965-0655

Éditeur

IKER

Édition imprimée

Date de publication : 1 octobre 1999

Pagination : $39-93$

ISBN : 2-84127-157-9

ISSN : $1273-3830$

Référence électronique

Bernard Oyharçabal, "Les prologues auctoriaux des ouvrages basques des XVle et XVIle siècles », Lapurdum [En ligne], Numéro Spécial 1 | 1999, mis en ligne le 01 juin 2010, consulté le 01 février 2020. URL : http://journals.openedition.org/lapurdum/1608; DOI : 10.4000/lapurdum.1608

Oyharçabal B. | IKER 
Bernard OYHARÇABAL

\section{LES PROLOGUES AUCTORIAUX DES OUVRAGES BASQUES DES XVI ${ }^{\mathrm{e}}$ ET XVII ${ }^{\mathrm{e}}$ SIËCLES}

L'objet de ce colloque étant de mieux connaître les conditions dans lesquelles la littérature classique basque se développa au XVII ${ }^{e}$ siècle, j'examinerai pour ma part certains des écrits de la périphérie des textes, que G. Genette (1987) a désignés sous le nom de paratextes, et que l'on rencontre également sous d'autres désignations comme périgraphie (Compagnon 1979 : 328), ou encore, en espagnol, preliminares (Spang, $1987: 322$ ).

Après certains travaux précurseurs, notamment pour la littérature du siècle d'or en Espagne celui de Porqueras Mayo (1957), au cours de ces dernières années, disons surtout au cours des années 80 , les historiens de la littérature, en particulier les spécialistes du XVI ${ }^{\circ}$ siècle, ou encore du Moyen Age en Espagne et en France, ont souligné l'importance de ces textes périphériques pour comprendre et interpréter les conditions de production et de réception des oeuvres. Certes, le thème n'était pas nouveau, mais il avait été abordé jusque-là dans une perspective principalement bibliographique (Cayuela 1996 : 08). En dehors de cette optique, illustrée notamment dans les études basques par Vinson dans sa bibliographie (1891), les paratextes basques ont peu été étudiés jusqu'ici, et ce colloque offre l'occasion de leur porter, du moins pour ceux de la période considérée, une attention particulière ${ }^{\text {. }}$.

Pour les ouvrages en basque publiés durant les $\mathrm{XVI}^{e}$ et $\mathrm{XVII}^{e}$ siècles, nous pouvons distinguer quatre types majeurs de paratextes ${ }^{2}$ : ceux relatifs aux éléments de nature éditoriale (titre, auteur, lieu, date et conditions d'impression, errata); les éléments de préciation de l'œuvre ou également de l'auteur dûs à des plumes autres que celle de l'auteur lui-même, dont notamment, dans le cas qui nous concerne ici, eu égard à la forte proportion d'ouvrages religieux, les approbations et permissions épiscopales qui constituent un sous-groupe caractéristique; les dédicaces de l'auteur, qui sont très fréquentes jusqu'à la seconde moitié du XVII ${ }^{e}$ siècle, et que J.-B. Orpustan examinera au cours de ce colloque, et enfin les prologues et avertissements au lecteur rédigés, soit par les auteurs euxmêmes (préfaces auctoriales, selon la dénomination de Genette), soit par les traducteurs en tant que prologuistes de leur travail de traduction ${ }^{3}$. Ce sont de ces derniers dont pour ma part je parlerai exclusivement.

Généralement les prologues des textes basques ne sont pas désignés autrement que par la mention du destinataire au datif, notamment par les formules Euskaldunei 'Aux Basques'ou Irakurtzaileari 'Au lecteur'. Parfois le terme abisua 'avis' est associé à la mention du destinataire, comme chez Etcheberri de Ciboure, et le terme prefacioa 'préface' apparaît également chez Gasteluçar alors que la forme antérieure classique de ces paratextes se modifie, et vient doubler l'avertissement au lecteur. Tous ces textes, que nous regroupons sous le nom 
générique de prologue, se caractérisent par les éléments suivants : i) ils sont rédigés par l'auteur; ii) ils visent à présenter l'ouvrage publié (ou la traduction réalisée) au lecteur sur un mode personnel et direct. Contrairement aux dédicaces, lesquelles sont adressées généralement à quelque personne de mérite ou d'importance, parfois dans le but de bénéficier de sa protection, voire de son aide financière pour la publication, ou encore pour rappeler que c'est à sa demande que l'ouvrage a été écrit, les prologues ne sont pas destinés à quelqu'un en particulier, sinon au lecteur, parfois socialement ou culturellement défini, mais toujours anonyme et virtuel, même lorsque, comme Montaigne dans ses Essais, il prétend avoir écrit son livre à la commodité particulière de [ses] parens et amis, et en aucune façon pour rechercher la faveur du monde.

Dédicaces et prologues forment par conséquent des paratextes de nature bien différente, même s'il advient à l'occasion que les premières soient rédigées de manière telle qu'on y retrouve l'essentiel des éléments des prologues. On peut mesurer la différence générique des deux types de paratextes en considérant dans la littérature basque par exemple Guero d'Axular et Onsa hilceco bidia de Tartas, qui disposent tous deux à la fois d'une dédicace et d'un avertissement au lecteur, de formats classiques pour la période.

Comme nous allons le voir, ces avertissements au lecteur sont relativement fréquents dans les ouvrages en basque à l'époque considérée et ils accordent presque tous une place importante à une question particulière : celle de la langue. Même si cet intérêt spécifique n'est pas inconnu ailleurs à certaines périodes, ainsi au milieu du XVI ${ }^{\mathrm{e}}$ siècle en France, c'est là, à n'en pas douter, une singularité des ouvrages basques, qui témoigne de la nature particulière, pour la plupart des auteurs, du choix de langue. Cette surpondération de l'aspect linguistique se retrouve, on le sait, tout au long de l'histoire de la littérature basque, et c'est d'ailleurs encore le cas dans une large mesure.

L'un des aspects pris par cette question de la langue se retrouve dans la différence que l'on peut constater entre la langue des textes (et généralement des prologues) et celle des dédicaces. Pour les textes que nous étudions ici, à de rares exceptions près, comme celle d'Oihenart (1657), sur laquelle nous reviendrons, les prologues sont en basque, comme les textes, alors que les dédicaces peuvent êtres rédigées dans une autre langue si leur destinataire n'est pas basque, soit dans le cadre d'une démarche bilingue comme dans la dédicace de Liçarrague à Jeanne d'Albret, soit en français uniquement comme dans la dédicace de Materre à l'Évêque de Bayonne, Claude de Rueil. La langue des paratextes de préciation est, elle, très variable (latin, espagnol ou français, basque).

\section{Les prologues dans les littératures des $\mathrm{XVI}^{e}$ et $\mathrm{XVII}^{e}$ siècles.}

$\mathrm{Au} \mathrm{XVI}{ }^{\circ}$ siècle, de nombreux auteurs font précéder leurs œuvres de prologues ou avertissements au lecteurs, suivant une conduite qui trouve sa source classique dans les textes dramatiques et poétiques, tels qu'ils furent théorisés par Aristote dans la Poétique et la Rhétorique (Tripet 1992 : 02; Montoya Martínez \& Riquer 1998 : 36). Des textes majeurs de la littérature française ou espagnole témoignent de l'importance de ces préliminaires. Du Bellay signale que sa Deffense et illustration de la langue françoise de 1549 avait été conçue comme le prologue à son ouvrage poétique Olive car ne pensant toutefois au commencement faire plus 
grand œuvre qu'un espitre et petit avertissement au lecteur, disjonction à laquelle ne procéda pas Ronsard, bien que les considérations adressées au lecteur apprentif en tête de la deuxième édition (posthume) de 1587 de La Franciade ont pu être considérées comme constituant un véritable art poétique (cf. Rigolot 1986). Le cas de Cervantes est tout aussi révélateur, qui écrit un prologue au $1^{\text {er }}$ livre du Quichote, pour railler cette pratique à laquelle il se soumet de mauvaise grâce et comme par obligation: Porque te sé decir que aunque me costó algún trabajo componerla [l'œuvre], ninguno tuve por mayor que hacer esta prefación que vas leyendo. Mucha veces tomé la pluma para escribille, y muchas la dejé, por no saber lo que escribiría; y estando una suspenso, con el papel delante, la pluma en la oreja, el codo en el bufete y la mano en la mejilla, pensando lo que diría, entró a deshora un amigo mio, gracioso, y bien entendido, el cual, viéndome tan imaginativo, me preguntó la causa y, no encubriéndosela yo, le dije que pensaba en el prólogo que habia de hacer a la historia de don Quijote. ${ }^{4}$

Qu'en est-il des textes basques? Au XVI ${ }^{e}$ siècle, Dechepare n'a pas de prologue ${ }^{5}$, et l'advertissement que Liçarrague fait figurer avant sa traduction du Nouveau Testament est un texte traduit faisant partie de l'original, contrairement à son adresse aux Basques (Heuscalduney). En fait, pour ces auteurs la question de la langue étant primordiale, et leurs dédicaces accordant à ce sujet une place importante, un tel préliminaire aurait fait en quelque sorte double emploi. C'est d'ailleurs un peu le cas chez Liçarrague qui, dans le texte s'adressant spécifiquement à ses lecteurs basques, et où il traite notamment des difficultés de sa tâche de traducteur, retrouve un point qu'il avait également développé dans sa dédicace à Jeanne d'Albret.

On s'étonnera bien sûr de l'absence d'un tel prologue chez Dechepare, très conscient de la nouveauté et de l'importance de son ouvrage du point de vue de la langue. Certes le thème linguistique et l'apport spécifique de son livre dans cette perspective ne sont pas ignorés, puisqu'il y consacre à la fois sa dédicace et les deux derniers poèmes de son recueil. Toutefois, par rapport à l'usage traditionnel des prologues au $\mathrm{XVI}^{\circ}$ siècle, manquent d'autres éléments que l'on aurait aimé y rencontrer, car sans doute nous auraient-ils permis de mieux comprendre les conditions dans lesquelles ses poèmes furent conçus et publiés. Tripet (1992: 202) voit dans le bref texte adressé Au lecteur par Montaigne dans ses Essais, une illustration des prologues classiques, en ceci du moins qu'il respecte la géométrie du genre fondée sur ce qu'il appelle le triangle du prologue, à savoir, le destinataire, l'œuvre et l'auteur. Pour qui Dechepare écrivait-il, à qui s'adressait-il? Dans quelles conditions choisit-il les thèmes qui furent les siens dans ses poèmes, et pourquoi leur donna-t-il cette forme? Comment se situait-il par rapport à sa propre production en tant qu'homme d'église, que poète de l'amour charnel, ou que responsable public, injustement accusé et emprisonné, ainsi qu'il l'assure dans son poème autobiographique? Ces questions restent largement sans réponse, et l'on peut penser qu'un avertissement au lecteur sur le modèle classique nous aurait fournit quelques indications ou indices nous mettant sur la voie. Ainsi, paradoxalement, l'absence de prologue chez Dechepare nous fait saisir l'importance que ces paratextes peuvent présenter pour comprendre la manière dont les textes sont produits et éventuellement reçus dans leur contexte.

Quels sont les textes de la littérature basque ${ }^{6}$ qui nous procurent de tels prologues jusqu'à la fin du XVII' siècle? Selon les ouvrages que j'ai pu consulter, ce sont, dans l'ordre chronologique, les suivants ${ }^{7}$ : 
Liçarrague (1571). Dans la traduction du Nouveau Testament une adresse Aux Basques (Heuscalduney); en tête de l'ABC une adresse $A$ tous ceux en charge de l'enseignement de la jeunesse et à leurs supérieurs (Gastetassunaren iracasteco cargüa dutenér eta goitico gucier).

Materre (1623). Un avertissement Aux Basques (Euscaldunei) repris certainement de la $1^{\text {re }}$ édition édition (perdue) de Dotrina christiana (1617); un avis Au lecteur (Iracurtçaileari) ajouté dans l'édition de 1623.

Beriayn (1621). Une adresse au lecteur en espagnol (Al lector) dans ce traité bilingue sur la manière d'entendre la messe.

Etcheberri de Ciboure (1627/1669 $)$. Dans le Manuel de Dévotion (Manual debotionezcoa), trois textes préliminaires en vers : l'avis au lecteur (Iracurtçailleari abisua); l'exhortation à l'apprentissage du Manuel (Manualaren ikhastera iraţ̧armendua); l'avis de l'auteur au lecteur dévot sur la manière du livre (Iracurţ̧aille devotari eguilleac liburu hunen maneraz abisua).

Haramboure (1635). Dans La Dévotion manuelle (Debocino escuarra) une adresse de l'auteur de l'ouvrage au lecteur (Irakurtzailleari obraren iabeak)

Axular (1643). Dans Guero (Après), un avis Au lecteur (Iracurtçailleari).

Oihenart (1657). Dans Les Proverbes basques recueillis par le Sr d'Oihenart, plus les poésies basques du mesme auteur, une préface rédigée en français en tête de l'ouvrage et précédant le recueil de proverbes, et un avertissement Av lectevr avant la seconde partie rassemblant les poésies basques.

Argaiñaratz (1665). Dans Le bréviaire des dévots (Devoten breviarioa), un avis aux dévots (Devotei).

Tartas (1666 \& 1672). Dans La voie pour bien mourir (Onsa hilceco bidia), une adresse Au lecteur (Iraccurtcaliari; même chose dans Les occupations dévotes de l'âme pénitente (Arima penitentaren occupatione devotaq).

Gasteluçar (1686). Dans Eguia catolicac salvamendu eternalaren eguiteco necessario direnac (Les vérités catholiques nécessaires pour réaliser son salut éternel), une préface (Prefacioa) et un avis (Abisua).

Comme on peut le constater, les ouvrages basques de la période considérée qui disposent d'un avertissement au lecteur sont relativement nombreux. Tous ne sont pas de même importance, et il convient de distinguer selon la nature des ouvrages, la période, les auteurs. Nous offrons en annexe les textes basques avec leur traduction française, et le lecteur pourra s'y référer pour en prendre connaissance. Dans les paragraphes qui suivront, je procéderai à certaines observations relatives au contenu de ces prologues de divers points de vue.

\section{Les prologues-types de Materre, Axular et Tartas}

Parmi les divers textes mentionnés, certains correspondent à une facture classique pour l'époque. Avec l'adresse aux Basques de Materre, probablement pré- 
sente dans l'édition de 1617 de Dotrina Christiana, c'est surtout le cas des prologues qu'Axular et Tartas firent paraître dans leurs ouvrages de morale religieuse Guero et Onsa hilceco bidia, genre de littérature dans lequel les auteurs affectionnaient particulièrement les paratextes en ce temps, ce qui avait suggéré à La Bruyère cette observation narquoise, qui figure dans ses Caractères : Si l'on ôte de beaucoup d'ouvrages de morale l'Avertissement au lecteur, l'Epître dédicatoire, la Préface, la Table, les approbations, il reste à peine assez de pages pour mériter le nom de livre (Les Caractères, Des ouvrages de l'esprit).

La structure de ces prologues s'établit autour des quatre éléments suivants, que l'on trouve chez les trois auteurs (sauf pour le dernier chez Materre) :

- circonstances expliquant comment l'auteur a entrepris son ouvrage : topos de l'auteur obligé;

- indications générales relatives au plan de l'ouvrage;

- discussions des questions de langue et des difficultés y attenant rencontrées par l'auteur;

- posture d'humilité de l'auteur : topos de la modestie.

Nous nous appuierons sur ces prologues pour examiner les conditions de réalisation de cette structure.

\section{Le topos de l'auteur obligé}

Le but du prologue est principalement de présenter au lecteur la posture que l'auteur entend prendre aux yeux du lecteur par rapport à l'œuvre et de définir le contenu de celle-ci. En réalité il s'agit là d'une actualisation des stratégies de rhétorique dont les auteurs classiques avaient clairement établi la double tâche : instruire (docere) et séduire (placere). Le prologuiste poursuit ainsi un double objectif : souligner l'intérêt de son propos afin d'attirer l'attention du lecteur (attentum parare), mais aussi, le séduire, et pour cela susciter chez lui la sympathie pour l'œuvre (docilem parare) et la bienveillance envers l'auteur (captatio benevolentiae), laquelle se gagne notamment en adoptant une attitude de modestie.

Il y a là comme une contradiction : l'auteur, d'une part, doit se diminuer au yeux du lecteur en tant qu'auteur, mais, d'autre part, il ne saurait évidemment associer son discours à ce propos de rabaissement, ce qui serait contreproductif. Cette contradiction est le plus souvent résolue dans les prologues ${ }^{9}$ par le recours à un procédé consistant à disjoindre l'auteur de l'œuvre, en mettant en scène des circonstances permettant cette dissociation. Nous en verrons une illustration presque caricaturale et à vrai dire quelque peu maladroite chez Tartas (1666).

Ce sont Axular et Tartas, dont les ouvrages, bien qu'ils relèvent de la réflexion religieuse, accordent aux conventions littéraires une place indéniable, qui se plient le plus clairement à ce jeu. Tout en revendiquant leur statut d'auteurs, ils présentent leur oeuvre comme le produit d'une action extérieure, et évoquent des circonstances, plus sûrement inventées que réelles, au moins chez Tartas, mais sans doute également chez Axular, qu'ils mettent en scène dans un style et un ton qui anticipent ceux du texte proprement dit.

Le texte d'Axular est bien connu, car les historiens de la littérature ont souvent considéré le récit des circonstances dans lesquelles Axular entreprit la rédaction de son ouvrage comme une allusion à un groupe de lettrés basques du 
Labourd se réunissant pour disserter des moyens de promouvoir une littérature religieuse de qualité dans la langue du pays (Villasante, 1979:68,77-78). Il est difficile de déterminer dans quelle mesure ces propos correspondent à une certaine réalité, ou s'il s'agit simplement d'une fiction conventionnelle. Car le procédé est bien connu qui fait que Tripet (1992) s'interroge lui aussi à propos des prologuistes français : Que dire des déclarations où l'auteur excuse la publication de son livre en disant (...) que ce sont ses amis qui ont insisté pour qu'elle se fasse (...) ? Rien n'exige que l'on doute, systématiquement, de la sincérité de telles déclarations; mais il faut reconnaître qu'elles permettent à l'auteur de sauver l'existence et la valeur de son ouvre par personne et par circonstances interposées, tout en respectant le topos de la modestie. (Montaigne et l'art du prologue au $X V T^{e}$ siècle, p. 13). Cette interrogation vaut tout aussi bien pour le prologue d'Axular qui débute ainsi :

Egun batez, compaiñia on batean, euscaldunic baicen etcen leccuan nengoela, eccarri çuen solhasac, içan cen perpausa, etçuela deusec ere hanbat calte eguiten arimaco, eta ez gorputceco ere, nola eguitecoen gueroco vtzteac, egunetic egunera, biharretic biharrera luçatceac. Eta on çatequeiela, gauça hunetçaz liburu baten, euscaraz, guztiz ere euscararic baicen etciaquitenentçat, eguitea; eta hartan, guero dioenac bego dioela eracustea, compaiñia berean galdeguin cen berehala, ea nori emanen ceican liburuaren eguiteco cargua. Eta bertce guztien artetic, hasi ceizquidan niri neroni aditcera emaiten, lehembician kheinuz eta ayeruz, eta guero azquenean, clarqui eta aguerriz, nic behar nituela, eguiteco hartan escuac sarthu. Ordea nola ezpainintcen neure buruaz fida, desencusatu nintcen ahal beçanbat. Baiña alferric, ceren hain cinez eta batetan lothu ceisquidan, non ezetz erraiteco bide guztiac, hertsi baitcerausquidaten. (Axular, Guero, Iracurtçailleari)

Un jour, alors que je me trouvais dans une compagnie agréable, composée uniquement de Basques, la conversation apporta le sujet, et le propos vint, que rien ne faisait plus de mal à l'âme, et même au corps, que le recul de l'accomplissement des devoirs, leur remise à plus tard de jour en jour, et de lendemain en lendemain. Et qu'il serait probablement utile de faire un livre en basque sur ce thème, destiné en particulier à ceux qui ne savent que le basque, et d'y montrer que celui qui dit plus tard dit jamais. Et parmi tous les présents, c'est à moi que l'on commença à faire comprendre, d'abord par signes et par allusions, puis, à la fin, clairement et ouvertement, qu'il me fallait prendre en mains cette tâche. Toutefois, comme je n'avais guère confiance en moi, j'essayais le plus possible de me faire excuser. Mais en vain, car on s'efforça si sincèrement et unanimement de me convaincre, qu'on me ferma toutes les voies de refus.

Tartas ne s'embarrasse pas de réalisme et a recours à un procédé également classique : celui du songe inspirateur, développé sur un mode naïf et ingénu, qui ne doit pas probablement pas être interprété au second degré, bien que le lecteur soit tenté de le faire (ambiguïté de registre qui, elle aussi, préfigure l'une des caractéristiques du texte lui même) :

NEVRE adesquidia, igarén vdan egun batez nangoela çuhaincé batén itçalbian neuré orenen errayten ninçala, loac harturic, eguindut neuré loan ametz handibat eta misteriosbat, iduritçen çautan neuré ametsian, iccusten niala guiçon eta emazte tropelabat goiti çelurat igaiten eta bertçé tropela bat oraino handiagoric beheiti ifernurat ioaiten eta erorten, gendé hec consideraturic batçiac gora, bertçiac behera ioaiten çirela, oihu eguindut eta heiagora orori, çer çen causa, edo çergatic batçiac goiti bertçiac beheiti ioaiten çiren : bere hala heldu da, botzbat çelutic eta emandu errapostu botçac ené oihia, eta heihagora ençunic, gende hetaric partebat goiti çelurat ioaiten çela, çeren beré herioaz, eta bere hilçiaz mundu hontan ordu honetz orhituric, eta herioac beccatu mortalic bateré gaberic gratiazco estatian atrapaturic, lurretic partitcen baitçiren; eta berçé parté guehiena beheiti ifernurat ioaiten çirela, çeren beré herioaz eta beré hilçiaz asqui ordu honéz orhitu faltaz, gratiazco estatutic campoan, 
herioac beccatu mortaléz betheric atrapaturic, lurretic partitcen baitciren hargatic cirela galdu, eta damnatu.

Loac eta ametsac, eta ametsaren errapostiac içituric, eta lotsaturic, iratçartu ninçan, eta hartu lumá escúra euscaldunen fauoretan euscaraz porogatçeco, onsa hilçeco bidia dela, herioaz, eta hilçiaz ardura orhitçia eta salbatçeco eztela bidé hoberic mundian. (Tartas, Onsa hilçeco bidia, Iraccurtçaliari)

Mon ami, alors qu'un jour, l'été dernier, je me trouvais à l'ombre d'un arbre à lire mes heures, m'étant endormi, j'ai fait dans mon sommeil un rêve grand et mystérieux; il me semblait que je voyais dans mon rêve une troupe d'hommes et de femmes montant au ciel, et une autre troupe, encore plus grande, descendant et chutant en enfer, et, considérant ces gens, les uns allant vers le haut, les autres vers le bas, j'ai crié, et poussé des clameurs : quelle était la cause de ceci et pourquoi les uns allaient vers le haut, les autres vers le bas; aussitôt, vint du ciel une voix qui, ayant entendu ma clameur et mon cri, répondit qu'une partie de ces gens montait au ciel parce qu'ils avaient quitté la terre s'étant souvenus assez tôt en ce monde de leur mort et de leur trépas, et la mort les ayant attrapés en état de grâce sans qu'ils aient aucun péché mortel, et que l'autre plus grande partie descendait en enfer, parce que, faute de s'être souvenus suffisamment tôt de leur mort et de leur trépas, ils avaient quitté la terre hors de l'état de grâce et la mort les ayant attrapés entièrement souillés de péchés mortels, et que pour cette raison ils s'étaient perdus et damnés.

Epouvanté et effrayé par mon sommeil, mon songe et la réponse de mon rêve, je me réveillai, et pris la plume à la main pour prouver au bénéfice des Basques que la manière de mourir bien consiste à se rappeler fréquemment de la mort, et qu'il n'existe pas de voie meilleure en ce monde pour se sauver.

Chez Materre, qui a rédigé un catéchisme sans prétention littéraire aucune, les choses se présentent différemment, car son travail est en réalité une œuvre pionnière. Avant lui, fort peu d'ouvrages avaient été publiés en basque, et on peut penser que ceux de Dechepare et de Liçarrague ${ }^{10}$, ne serait-ce que pour des motifs de contenu, ne devaient pas être d'accès facile à cette époque en Labourd. De plus, Materre n'était pas basque, et il était bien conscient du paradoxe que constituait son statut d'auteur en langue basque. C'est par rapport à cette situation qu'il se situe dans son prologue de la première édition (1617) adressée aux Basques :

Miretsico duçue agian nic (Euscal-herrico ez naicelaric) Euscaraz esquiribatceco ausartciaren hartcea. Baiña baldin considera ba-dadi edirenen duçue eztela gauça hunetan ausartciaric, eta ez cer miretsiric : aitcitic bertcela eguin ba-nu miretsi behar çatequeyela eta erran ahanci citçaitala neure eguinbidea. Ceren Iaincoac niri hitzcunça hunen ikasteco ance appur bat eman derautanaz gueroz, iduritcen çait hoben nuqueyela, eta ere ezagutça gutitaco eta esquer gabe içanen nincela, baldin Euscalherrian ikassia Euscal-herrico probetchutan emplegatu ez-panu. (Materre, Dotrina christiana, Euscaldunei)

Vous vous étonnerez peut-être que, n'étant pas du Pays Basque, j'aie l'audace d'écrire en basque. Mais si on considère cette chose vous verrez qu'il n'y a en elle nulle audace, et rien pour s'étonner : au contraire c'est si j'avais fait autrement qu'il aurait fallu s'étonner et me dire que j'avais oublié mon devoir. Car puisque Dieu m'a donné suffisamment de dispositions pour apprendre cette langue, il me semble que j'aurais commis une faute, et que j'aurais été peu reconnaissant et ingrat, si je n'avais pas employé au bénéfice du Pays Basque ce que j’y avais appris. 
Comme on le voit, Materre, sans recourir aux procédés rhétoriques du type de ceux d'Axular et Tartas, entend malgré tout lui aussi se présenter comme un auteur contraint, c'est-à-dire dont l'entreprise relève de l'obligation éthique et sacerdotale. Ayant fait allusion à la parabole du serviteur paresseux de l'évangile il poursuit, en jouant de l'ambiguïté du terme talentu 'talent', entendu d'une part au sens de monnaie et associé à l'argent dans l'évangile, mais compris d'autre part au sens de don ou d'aptitude et évoquant la capacité à apprendre les langues dans son cas :

Euangelioco cerbitçari alfer hura gaztigatu çuen bere nabusiac, ceren irabacian erabiltceco errecibitu çuen talentua eta dirua estalia eta ehortcia eduqui çuen. Handic içan naiz ni ere beldur hala gertha cequidan, baldin Euscaraz minçatceco ardietsi dudan talentua eta iaquina arima irabacian emplegatu gabe ehortcia eta gordea eduquitcen ba-nuen. Eta etçait iduri asco dela Cadiratic predicatuz probetchu eguitea baiña are vste dut esquiribuz ere behar dela enseyatu eta trabaillatu. (Materre, Dotrina christiana, Euscaldunei)

Dans l'évangile, le serviteur paresseux fut puni par son maître, car il avait gardé caché et enterré le talent et l'argent qu'il avait reçus afin de le faire fructifier. J'ai craint qu'il ne m'arrivât la même chose, si je tenais caché et enterré, sans l'employer au bénéfice des âmes, le talent et le savoir dont j'ai été doté pour parler basque. Et il ne semble pas qu'il suffise d'en tirer profit en prêchant de la chaire, mais je crois qu'il faut s'y employer et y travailler par écrit également.

\section{Indications relatives à la structure de l'ouvrage}

Les trois auteurs mentionnés donnent ensuite quelques indications sur le contenu de leurs œuvres ou leur structure : il s'agit de la partie spécifiquement informationnelle du prologue, mais à laquelle en réalité on n'accorde guère d'importance. Les auteurs procèdent de façon passablement elliptique.

Chez Axular et Tartas les indications portent sur les principales divisions de leur texte. On sait que dans Guero cette partie du prologue a donné lieu à certaines difficultés d'interprétation dont traitera Haritschelhar au cours du colloque (cf. également Salaberri 1998). En effet, il est clair qu'au moment où le prologue a été rédigé, Axular envisageait de ne publier qu'une première partie de son essai, sans que l'on sache maintenant avec certitude si tel a été le cas, ou si finalement l'ouvrage complet avait été publié comme l'indique, en contradiction avec le prologue, le titre de l'ouvrage.

Eta hala deliberatu nuen, buru-eragotz carri beçala, liburutto baten, bi partetan partituric, guero, hunen gaiñean eguitera.

Eta nahi nituzqueyen bi parteac elccarrequin, eta batetan athera. Baina iccussiric cein gauça guti edireiten den euscaraz esquiribaturic, gogan behartu naiz eta veldur$t u$, eztiren bideac asco segur eta garbi, baden bitartean cenbait trabu edo behaztopa harri. Eta halatan hartudut gogo, lehenbicico parte hunen, lehenic venturatçeco, eta berri iaquitera beçala aitcinerat igortceco. Hunec cer iragaiten den, cer beguitarte içaiten duen, eta nor nola mintço den, auisu eman diadaçan. Guero auisu haren arauaz ethorquiçunerat gouernatceco : Eta bi garren partearen camporat atheratceco, edo barrenean guelditceco eta estaltceco. (Axular, Guero, Iracurtçailleari)

Et ainsi je décidai, comme un défi pour mon esprit, de faire ce livre, en le divisant en deux parties.

Et j'aurais voulu publier ces deux parties ensemble et en même temps. Mais voyant que peu de choses avaient été écrites en basque, je me suis inquiété et j'ai pris peur que la route ne soit pas assez sûre et claire, et qu'il n'y ait sur le chemin quelque obstacle 
et pierre de trébuchement. Et ainsi, j'ai décidé d'aventurer d'abord cette première partie, et de l'envoyer par devant en manière d'éclaireur. Afin qu'elle m'avise de ce qu'il advient, de l'accueil qu'elle reçoit, et de la manière dont on en parle. De façon à agir en fonction de cet avertissement par la suite : ou bien en publiant cette seconde partie, ou bien en la gardant par-devers moi, et en l'y celant.

Dans Onsa hilceco bidia de Tartas, le plan en quatre parties, fondé sur la nature de l'argumentation développée, est exposé directement et de manière très succinte :

Edirenen duçu laur capitulu ené liburian, lehenian porogatcendut paganoen erranaz, bi garrenian, legué çaharreco escritura saindiaz.; hirur garrenian legué berriaz, eta eliçaco doctor saindiéz, laur garrenian laur arraçoin differentéz, onsa hilçeco bidia dela herioaz, eta hilçiaz orhitcia. (Tartas, Onsa hilçeco bidia, Iraccurtçaliari)

Vous trouverez quatre chapitres dans mon livre; dans le premier, je prouve par les dires des païens, dans le second, grâce à la sainte écriture de la vieille loi, dans le troisième en vertu de la loi nouvelle et des saints docteurs de l'église, dans le quatrième au moyen de quatre différentes raisons, que la manière de bien mourir consiste à se rappeler de la mort et du trépas.

Malgré sa briéveté, le propos de Materre est fort intéressant. En effet, contrairement à Axular et Tartas, il ne se contente pas de fixer comme objectif à son ouvrage l'instruction religieuse, comme il est normal pour un ouvrage de doctrine catholique, il y a ajoute spécifiquement une visée de fondateur et propagateur de l'écrit basque :

Eta nola lanac cimendutic behar baitu hassi, eta gure salbamenduco obraren cimendua baita Doctrina Christiana, halatan nic ere, handic hasten naicela, hartu dut gogo liburutto hunen eguiteco, eta iendartera atheratceco, hunetan (bertce eracusleric eztenean) ikus dadin laburzqui cer-ere sinhetsi, obratu, eta escatu behar baita; Eta guero ikus dadin halaber nola behar den Euscara esquiribatu eta iracurtu. (Materre, Dotrina christiana, Euscaldunei)

Et comme le travail doit commencer par les fondements, et le fondement de notre œuvre salvatrice étant la doctrine chrétienne, j'ai moi aussi, commençant par là, formé le projet de faire ce petit livre, et de le mettre à la disposition du public, afin qu'on y trouve (quand il n'y a pas d'autre enseignant) ce qu'il faut croire, œuvrer et demander; et qu'ensuite l'on voie de même comment il faut écrire et lire le basque.

Ainsi Materre affiche comme but de son projet, à côté de l'enseignement spirituel, comment il faut écrire et lire le basque. Depuis la Réforme, comme en témoigne en Pays Basque l'ABC de Liçarrague, l'encadrement religieux des populations est associé à des obligations d'alphabétisation. Materre, dont l'action doit être située dans la cadre de la réaction post-tridentine, se trouve néanmoins confronté à un problème de nature linguistique, personnel d'abord, puisqu'il lui a fallu apprendre le basque ainsi qu'il l'indique dans son prologue, et plus général ensuite, car il n'existe pas de standard de langue écrite. Il est probable en effet que certaines couches de la population du Labourd au début du XVII ${ }^{e}$ siècle, et plus généralement du Pays Basque, étaient alphabétisées en basque, mais d'une façon plus ou moins grossière, que nous laissent entrevoir les lettres que la Dame d'Urtubie adressa en 1597-1598 à son correspondant Juan Velázquez, Gouverneur général du Guipuscoa ${ }^{11}$. On peut sans doute interpréter l'indication de Materre comme manifestant la nécessité qu'il perçoit d'une fixation de normes de la langue écrite, problème que, d'une part en tant qu'apprenant, d'autre part en tant que prédicateur convaincu de l'importance de l'écrit (rappelons qu'il avait déjà publié un ouvrage de dévotion en français avant sa venue en Labourd), il était bien placé pour percevoir. 


\section{Le topos de la modestie}

Pour se présenter au lecteur sous un jour favorable, les prologuistes ont souvent recours au thème de la modestie, consistant en particulier pour l'auteur à avouer par avance ses fautes et faiblesses dans le traitement du sujet.

Absent chez Materre, ce qui se comprend étant donné la nature peu personnelle de son ouvrage, le thème de l'humilité est surtout présent chez Axular. Ce dernier assure d'abord qu'il y aurait certainement des auteurs plus aptes que lui à entreprendre un tel ouvrage, mais qu'il espère que l'audace dont il fait preuve lui sera pardonnée car il s'agit d'une œuvre pionnière :

Badaquit anhitzec miretsicoduela eta edirenen arrotz eta estraiñio, ni lan huni lotcea. Ceren anhitz içan baita orainocoan, eta baita orai ere, ni ez beşalacoric, ni baiño hunetaco gai agoric, eta ançatsu agoric, ezpaitute guztiarequin ere, orainocoan, hunelaco materiatan, hunela ausartciaric eta escu dantciaric hartu. Baitirudi ecen asco behar liçatequeyela arraçoin haur ene guibelatceco eta gueldi aracitceco ere. Baiña ene contra dela dirudien arraçoin hunec beronec, ni esporţ̧atcen eta aitcinatcen nau, hunec bihotz emaiten deraut, haur edireiten dut nic neure alde eta fabore, ceren enseiucarrean beşala eguiten diren lehenbicico obrèc eta enseiuec, cembait hutz eta falta içanagatic ere, badirudi ecen, ceren lehenac diren, barccaquiçun direla, eta bat bederac disimulatceco, ez iccussi iduri eguiteco, eta are desencusatceco dituela. (Axular, Guero, Iracurtçailleari)

Je sais que beaucoup s'étonneront et trouveront inattendu et étrange que j'entreprenne un tel travail. Car ils ont été nombreux jusqu'ici, et ils le sont encore, ceux qui, différents de moi, plus capables et plus compétents que moi, n'ont pas eu malgré tout jusqu'à maintenant l'audace et la hardiesse de pénétrer en telle matière. Il semblerait que cette raison devrait être suffisante pour me retenir et m'arrêter. Mais cet argument qui semble m'être contraire, m'aiguillonne et me pousse à aller de l'avant, il m'encourage, et plaide en ma faveur, car, quand bien même les œuvres et tentatives que l'on fait comme à l'essai contiennent quelques fautes et faiblesses, il semble que celles-ci, parce qu'elles sont les premières, sont pardonnables, et que chacun est en mesure de les dissimuler, de les ignorer, et même de s'en faire excuser.

La posture de l'auteur modeste est utilisée à nouveau par Axular à la fin du prologue dans un argument conventionnel, typique des prologues religieux où les mérites éventuels de l'ouvrage doivent être attribués à l'inspirateur divin :

Eta baldin halatan eta orduan, bat ere goçoric edo çaphoreric edireiten badioçu, ceren hura guztia iaincoaganic heldu baitateque, eta ez eneganic faltaric baicen, hari esquerrac errenda iatçotçu, eta nitçaz ere othoitz eguiteaz, arren othoi, orhoit çaiteci. (Axular, Guero, Iracurtçailleari)

Et si vous lui trouvez alors [au livre] quelque douceur et saveur, comme tout ceci lui sera venu de Dieu, et non de moi, sinon les fautes, rendez-lui grâces, et, souvenezvous, je vous en prie, de prier pour moi également.

Tartas également sacrifie à la convention de l'humilité, mais dans une îormule rapide et passablement maladroite propre à décourager le lecteur :

Ené triuaillu appurrac eztu meritatçen çuc phena har deçaçun haren iraccurtçeco, baina çure salbamendiaren amorioac, eta desirac, eman derauté coraie, haren camporat idoquiteco, eta hari arguiaren emaiteco. (Tartas, Onsa hilceco bidia, Iraccurţ̧aliari)

Mon modeste travail ne mérite pas que vous preniez la peine de le lire, mais le souhait et le désir de votre salut m'ont donné le courage de le rendre public et de lui donner le jour. 
Un auteur s'éloigne quelque peu de cette attitude convenue et profite du prologue pour exprimer son attente d'une reconnaissance, au moins posthume, de la part de ses compatriotes. Il s'agit de Gasteluçar qui, ayant mis en vers basques des hymnes latins pour que les marins basques puissent les chanter, attend de ses compatriotes une certaine gratitude :

... eta hek prinzipalki konsideraturik, deliberatu dut liburu hunen egitera; erranen baitute batzuek, bizi zenean orhoitu zen bere herriaz, eta ez zitzaion ahantzi hiltzerakoan, bere señalleak emanik joan baita. Ezen nola plazer hartzen baitute itsasoan latiñez Elizako himnoen kantatzeaz, atsegin gehiago izanen dutela ${ }^{12}$ himno beren ezkaraz errateaz, aire berean ezkaraz ematen tut; eta gaiñerako bersuen airea komunzki gustiek badakite. (Gasteluçar, Eguia catolicac, Abisua)

... et c'est en ayant principalement ces derniers [les marins basques] à l'esprit que j'ai décidé d'écrire ce livre. Ainsi certains diront : lorsqu'il vécut, il se souvint de son pays, et il ne l'oublia pas non plus à l'heure de mourir, car il est parti en laissant son empreinte. En effet, comme les marins prennent plaisir à chanter en latin les hymnes de l'église lorsqu'ils sont en mer, je les traduis en basque sur le même air, pensant qu'ils auront encore plus de plaisir à les dire en basque.

\section{Les considérations linguistiques}

L'une des caractéristiques des prologues des textes basques est la place qu'y prend la question de la langue. La plupart des auteurs y font référence.

La question de la langue est d'abord abordée à travers la question du standard. Ce problème est mentionné par la plupart des auteurs prosélytes voulant s'adresser à un lectorat basque transprovincial : Liçarrague, Materre, Haramboure, Axular, Tartas, ou même plus restreint, comme chez Beriayn.

Il s'agit pour eux, soit de souligner la difficulté de la tâche comme chez Liçarrague ou Axular, soit d'indiquer la solution pour laquelle ils ont opté. Tous précisent d'ailleurs les limites de leur proposition, étant donné l'absence ou le peu de tradition.

On sait que c'est chez Liçarrague qu'un effort en vue de l'élaboration d'un standard littéraire est le plus manifeste. Dans son avis aux Basques il ne dissimule pas la difficulté qu'il a dû affronter :

Gaineracoaz den becembatean, batbederac daqui heuscal herrian quasi etche batetic bercera-ere minçatceco manerán cer differentiá eta diuersitatea den : raçoin hunegatic sensu eguiazcotic aldaratu gabe, lengoageaz den becembatean ahalic guehiena, guciey adi eraciteari iarreiqui içan gaitzaitza, eta ez choil edocein leku iaquineco lengoage bereciri. (Liçarrague, Heuscalduney)

Pour le reste, chacun sait quelle diversité et variation il existe en Pays Basque, presque d'une maison à l'autre, dans la manière de parler : pour cette raison, en ce qui concerne la langue, nous nous sommes attachés, sans nous éloigner du sens véritable, à faire comprendre le plus possible à tous, et non à suivre le parler particulier d'un lieu donné, quel qu'il soit.

L'objectif fixé par Liçarrague (faire une traduction fidèle permettant à tous de comprendre le plus possible) était ambitieux s'agissant de la traduction du Nouveau Testament dans une langue dont il précise bien dans sa dédicace à Jeanne d'Albret qu'elle était des plus stériles et diuerses, et du tout inusitée du moins en traduction. 
Liçarrague ne donne aucun détail quant aux difficultés rencontrées et aux solutions qu'il a privilégiées, indiquant simplement dans son adresse aux Basques que la variation dans les modes de parler basque est extrême, car observable presque d'une maison à l'autre, et que pour sa part il s'est efforcé de ne pas opter pour une solution localiste. Liçarrague utilisant le terme de heuscal herria (le pays basque), et désignant la communauté des Basques sous le terme de nation basque, doit-on penser qu'il tenait compte de tous les Basques pour créer son standard ${ }^{13}$ ? Probablement pas. Sa traduction tient compte à l'évidence des dialectes orientaux et notamment labourdins et souletins (un lexique destiné aux lecteurs souletins est inclus à la fin du Nouveau Testament), mais aucun effort d'adaptation linguistique en faveur d'éventuels lecteurs occidentaux, guipuscoans ou biscayens, n'est perceptible.

Chez les autres auteurs qui mentionnent la question dialectale, l'attitude qui prévaut suit le modèle de Dechepare : on utilise le basque du dialecte que l'on connaît le mieux. Cette option est clairement exprimée par Materre :

Gaiñeracoan badaquit Euscal-herrian añhitz moldez minçatcen direla, eta nor bere herrico Euscara çaicala hoberenic eta ederrenic. Eta handic gogoac emaiten deraut ene esquiribatceco molde haur etçayela guztiei ongui idurituco : Baiña nahi dut iaquin deçaten halacoec nic hitzcuntça hunetan daquidana Saran ikassia dudala, eta hango Euscara ongui erabiltcen ba-dut ez naicela gaitz erraiteco, eta ez arbuyatceco, ceren ez paitaquit nic hangoa baicen. (Materre, Dotrina christiana, Euscaldunei)

Pour le reste je sais qu'on parle en Pays Basque de bien des manières, et que chacun trouve son basque plus beau et meilleur. Et en conséquence de ceci il me vient à l'esprit que ma manière de m'exprimer ne paraîtra pas bonne à tous. Mais je veux que ceux-là sachent que ce que je sais en cette langue je l'ai appris à Sare, et si j'emploie bien le basque qu'on y parle, je ne dois pas être dénigré, et méprisé, car je ne connais pas d'autre basque que celui-là.

Materre se fait peut-être l'écho d'une controverse relative à la qualité des dialectes lorsqu'il évoque l'adéquation de son option. Il montre cependant un certain dédain pour ce sujet, et refuse de s'engager sur un débat où seraient mis en rivalité les différents dialectes.

Ordea ea Saraco Euscara denz Euscal-herrico hoberena eta garbiena, ez naiz ni hartan sartcen, bat-bederac emanen du bere iduriric. (Materre, Dotrina christiana, Euscaldunei)

Quant à savoir si le basque de Sare est le plus pur et le meilleur du Pays Basque, c'est un sujet que je n'aborderai pas, et chacun dira selon son opinion.

L'existence d'un débat de nature proprement linguistique est confirmé par une remarque de Haramboure dans son avis au lecteur, dans laquelle il revendique l'emploi de sa propre langue, fût-elle défectueuse aux yeux de certains ${ }^{14}$ :

Eguiazqui ençun dut eta badaquit batçuec minçatce mueta hau arbuiatcen dutela, berriz bercec bere herrietaco hizcunçaz nahi luquetela : baina bercela eguinic laudorioac baino neure herrico minçaiaz eguinic baiac gogoticago pairatuco ditut, halakotz ezteçala nihorc mirex baldin nahastecatuqui minço ezpanaiz. (Haramboure, Debocino escuarra)

J'ai vraiment entendu et je sais que certains méprisent cette manière de parler, et que d'autres préfèreraient l'emploi de la langue de leurs contrées : mais je supporterai mieux les reproches d'avoir écrit dans la langue de mon pays, que les louanges reçues si j'avais procédé autrement. Pour cette raison que nul ne s'étonne si je n'use pas d'une langue mélangée. 
Il est difficile d'interpréter ces propos, dits avec une certaine insistance (Eguiazqui ençun dut eta badaquit... J'ai vraiment entendu, et je sais...). $\mathrm{Y}$ eut-il deux types d'opposition comme le laisse penser l'emploi de la formule batçuec... bercec... 'les uns..., les autres...' : l'une portant sur la langue ellemême, c'est-à-dire le fait même de publier des ouvrages de dévotion en basque; l'autre, interne à la langue basque, concernant le choix dialectal?

La première opposition est peu documentée durant cette période, et elle n'a pas été relevée par les historiens de la littérature basque. Pourtant, si les témoignages d'une hostilité à l'emploi du basque dans les écrits religieux en Labourd à cette époque sont peu nombreux, ils existent. Ainsi, huit ans avant la publication de l'ouvrage de Haramboure, la dédicace d'Etcheberri à Claudius de Rueil, Evêque de Bayonne, en tête du $1^{\text {er }}$ livre de Manual devotionezcoa $(1627 / 1669)$ indique que ces publications ont pu faire naître des incompréhensions et des critiques. Je traduis ici les derniers distiques de cette dédicace :

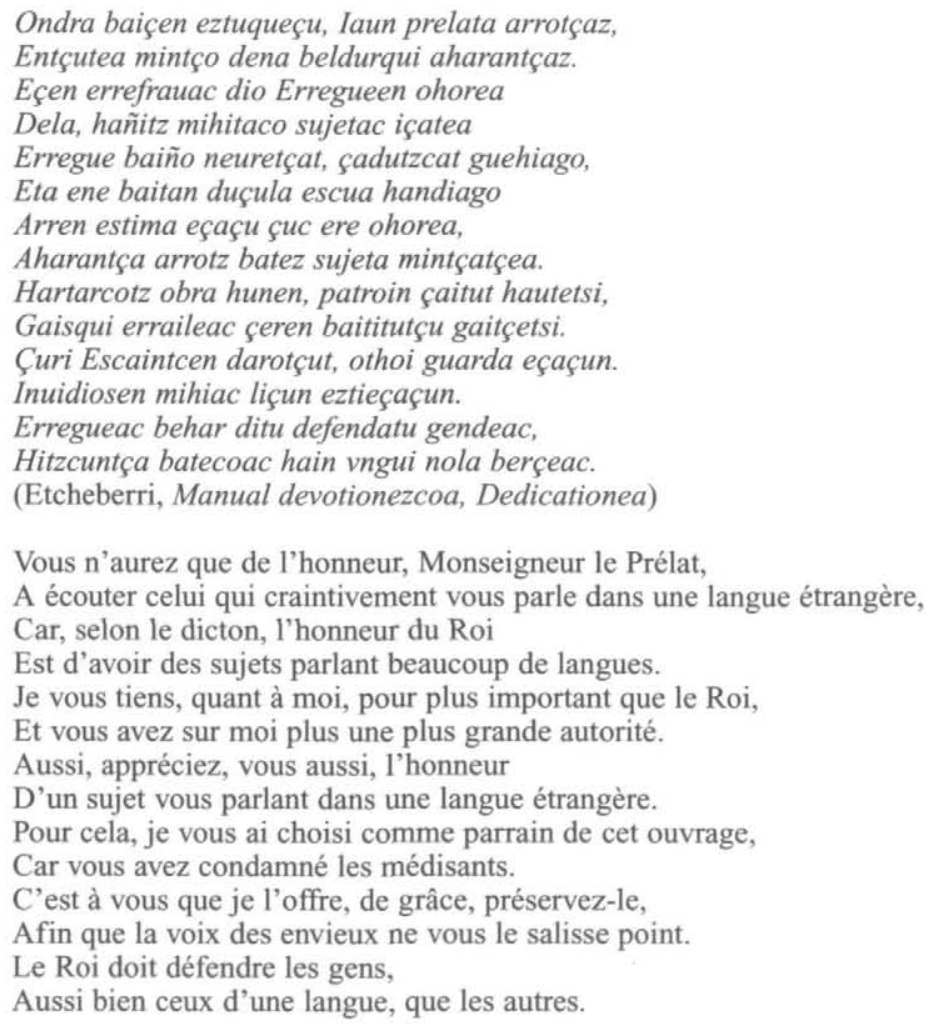

En faisant la part aux postures des dédicaces dans lesquelles la bienveillance du destinataire est parfois mise en relief par une allusion à la présence d'adversaires et d'envieux sans doute exagérée, le texte, à mon sens, ne laisse guère de doutes : il devait exister dans les milieux religieux un courant peu favorable à ces publications en langue basque ${ }^{15}$, et Etcheberri plaide clairement ici en faveur du plurilinguisme, demandant que l'Eglise ne fasse pas de discrimination linguistique, et suive l'exemple de l'Etat, dont les obligations en cette matière sont joliment formulées : Erregueac behar ditu defendatu gendeac / Hitzcuntça batecoac 
hain vngui nola berçeac 'Le Roi doit défendre les gens / Aussi bien ceux d'une langue, que les autres'. L'auteur s'adresse à l'évêque en basque, bien que celui-ci ne soit pas bascophone (contrairement à ce qu'avait fait Materre dix ans plus tôt, lequel avait rédigé la dédicace de sa doctrine à ce même évêque, en français). Il justifie son attitude, que d'aucuns pouvaient juger sans doute offensante (la dédicace n'est pas traduite dans l'ouvrage), en demandant au prélat de considérer cela comme un honneur : Estima eçaçu çuc ere ohorea / Aharantça arrotz batez sujeta mintçatçea 'Aussi, appréciez, vous aussi, l'honneur / D'un sujet vous parlant dans une langue étrangère'.

Cette interprétation est confirmée par les vers de S. de Hirigoity en l'honneur du même Etcheberri, figurant en tête de Noelac ouvrage publié à la même période ( $1^{\text {te }}$ édition en $1630 ;$ cf. Atutxa dans ce volume $)^{16}$. En effet, à côté des éloges, figurent des propos désignant des adversaires du basque comme étant des étrangers, sans autre précision : Erdaldunak ahal doazke zein bere herritara / Gogat eginik, galduko eztutela eskara 'Les étrangers ne sachant pas le basque peuvent s'en aller chacun dans son pays / S'étant résignés à ce qu'ils ne feront pas disparaître le basque'. C'est sans doute dans le cadre de ce conflit linguistique qu'il faut situer une partie des propos de l'auteur de Debocino eskuarra dans son avis.

Le second membre de la phrase de Haramboure désigne ensuite comme opposants ceux qui préfèrent la langue de leurs contrées : qui étaient-ils? S'agit-il ici encore de gens qui, à côté de ceux méprisant le basque, souhaitaient que l'on rédigeât les manuels catholiques dans une autre langue? Ou bien y a-t-il eu une seconde opposition relative, elle, non au basque, mais au choix du dialecte utilisé par Haramboure, correspondant à la variété de Sare? Que voulait dire précisément ce dernier en manifestant son refus de parler nahastecatuqui, lit. 'de manière mélangée'? S'il s'agissait d'une question dialectale ${ }^{17}$, comme nous aurions tendance à le penser, non sans quelques hésitations, on ne voit guère de concurrents hors du Labourd en cette première partie du XVII ${ }^{e}$ siècle, notamment dans les cercles cléricaux principalement concernés ici, puisque le premier ouvrage de nature religieuse publié dans un autre dialecte que le labourdin n'apparaîtra que trente ans plus tard ${ }^{18}$ avec Tartas. Il est vrai que l'ouvrage de Haramboure, certainement rédigé à la demande de l'Évêque de Tarbes, S. D'Tharce, comme dit dans une note précédente (note 14), visait peut-être un public plus large que ceux destinés aux zones situées en Labourd ou dans sa proximité bas-navarraise, puisque parmi les approbateurs figure Conget, curé de Tardets et chanoine d'Oloron ${ }^{19}$. Quoi qu'il en soit, on imagine difficilement qu'une rivalité linguistique entre Sare et Saint-Jean-de-Luz ou Ciboure ait pu prendre une aussi vilaine tournure, car relativement aux autres oppositions dialectales, celle-ci ne parait pas telle qu'elle ait pu faire naître un tel rejet. Ou bien ceci masquait-il alors d'autres rivalités, plus personnelles, peut-être quelque conflit ou antagonisme avec Etcheberri de Ciboure, lequel avait lui aussi publié quelques années plus tôt un manuel de dévotion dont Haramboure ne fait aucune mention? La question devra certainement être revue.

Le problème de la diversité linguistique est traité plus en détail par Axular, en même temps que celui de la différence des notations orthographiques. Mais on se situe dans le prolongement d'un pensée semblable à celle exprimée par Materre, avec parfois une réelle proximité dans les formulations de telle sorte que se renforce l'idée qu'Axular avait dû certainement voir de près, sinon inspirer dans cer- 
taines formulations, l'ouvrage du franciscain (dont il fut l'un des deux examinateurs en 1616).

Axular utilise également le terme euskal herria au singulier mais il lui donne le contenu historique moderne qui s'affirmera au XIX ${ }^{e}$ siècle. Il y associe en effet, explicitement, les sept provinces historiques, indiquant que le basque est présent dans chacune d'entre elles, dans une formulation pouvant donner d'ailleurs à entendre, de manière fort inattendue ${ }^{20}$, que la langue basque est également utilisée en d'autres lieux :

Badaquit halaber ecin heda naitequeyela euscaraco minçatce molde guztietara. Ceren anhitz moldez eta differentqui mintçatcen baitira euscal herrian. Naffarroa garayan, Naffarroa beherean, Çuberoan, Laphurdin, Bizcayan, Guipuzcoan, Alabaherrian, eta bertce anhitz leccutan. (Axular, Guero, Iracurtçailleari)

Je sais de même qu'il m'est impossible d'atteindre toutes les manières de parler basque. Car on parle différemment et de beaucoup de manières diverses dans le pays basque : en Haute-Navarre, en Basse-Navarre, en Soule, en Labourd, en Biscaye, en Guipuscoa, en Pays d'Alava, et dans bien d'autres endroits.

Les exemples concrets de variations mentionnés par Axular dans son avis concernent le lexique et l'orthographe, mais jamais la morphologie fonctionnel$\mathrm{le}^{20}$, contrairement à Liçarrague qui voyait dans la désinence du datif des syntagmes nominaux déterminé par l'article pluriel un marqueur dialectal significatif (-er vs $-e i)^{22}$. Axular cite neuf paires de mots en variation dialectale ${ }^{23}$, et si l'on s'en tient à ces exemples ils concernent surtout la partie orientale du Pays Basque (Haute-Navarre incluse ${ }^{24}$ ) : behatzea vs so egitea 'regarder', samurtzea vs haserretzea 'se fâcher', ilkitzea vs jalgitea 'sortir', athea vs bortha 'porte'; erraitea vs esatea 'dire'; irakurtzea vs leitzea 'lire'; liskartzea vs ahakartzea 'se quereller'; hauzoa vs barridea 'le voisin', aitonen semea vs zalduna 'le chevalier'.

Pour Axular, la source des variations dialectales est historique et elle est directement associée aux rattachements politiques :

Eztituzte euscaldun guztiec legueac eta azturac bat, eta ez euscarazco mintçatcea ere, ceren erresumac baitituzte different. (Axular, Guero, Iracurţ̧ailleari)

Tous les Basques n'ont pas les mêmes lois et usages, ni la même manière de parler, car ils appartiennent à des royaumes différents.

Il fournit également cette explication pour expliquer la variation dans les systèmes de transcription orthographique, illustrée avec la fricative palatale sourde orthographiée aujourd'hui $x$. Les formes mentionnées par Axular font clairement référence à un usage ayant sa source dans la tradition orthographique du castillan, mais que Materre avait introduit dans les écrits basques, peut-être sous l'influence d'Axular lui-même (Mujika 1997 : 181). En effet cette consonne, orthographiée $c h$ ou $x$ chez Dechepare et toujours $c h$ chez Liçarrague, apparaît aussi transcrite $g$ (devant les voyelles d'avant $e$ et $i$ ) ou $j$ (devant les autres voyelles) chez Materre (à côté de $x$, qu'il emploie également) ${ }^{25}$ :

Bada esquiribatceaz denaz beçan batean ere ez naiz eguiteco gabe. Ceren bada hunetan ere differentcia. Batac esquiribatcendu chehero, bertceac gehero. Batac chedea, bertceac gedea. Batac ichilik, bertceac igilik. Batac lachoa, bertceac lajoa. Batac choil, bertceac, joil. Batac quecho, bertceac quejo. Batac chuchen, bertceac, jujen. Eta hunela bada, bertceric ere cembait hitz, batac eta bertceac, norc bere herrico edo erresumaco arauaz diferentqui esquiribatcen baitituzte. (Axular, Guero, Iracurtçailleari) 
Et en ce qui concerne l'écriture également je ne suis pas sans travail. Car en cette matière aussi il y a des variations. L'un écrit chehero, l'autre gehero. L'un chedea, l'autre gedea. L'un ichilic, l'autre igilic. L'un lachoa, l'autre lajoa. L'un choil, l'autre joil. L'un quecho, l'autre quejo. L'un chuchen, l'autre jugen. Et ainsi encore d'autres mots, que les uns et les autres écrivent différemment, chacun selon les us de son pays ou son royaume.

Ayant constaté la variation, quelle solution propose Axular pour définir le basque de son ouvrage? Son attitude est sensiblement différente de celle de Liçarrague. Axular, contrairement à ce que l'on dit parfois, n'a pas pour objectif de construire un basque unifié comme l'on dit aujourd'hui. En fait, à l'instar de Materre, il ne dissocie pas les questions proprement dialectales de celles liées à la qualité (la perfection selon les termes de l'époque), et il privilégie par conséquent la langue qu'il connaît le mieux :

Baiña ceren comunzqui, hala esquiribatcea, nola mintçatcea, nori berea iduritcen baiţ̧aica hoberenic eta ederrenic : eta ene haur ezpaita çurea beçala : ez, othoi, hargatic arbuya eta ez gaitz erran. Hunetçaz content ez paçara, eguiçu çuc ceure molde$r a$, eta çure herrian vsatcen eta seguitcen den beçala. Ceren ez naiz ni hargatic beccaiztuco, eta ez mutturturic gaitzez iarrico. (Axular, Guero, Iracurţ̧ailleari)

Mais comme communément en matière d'écriture et de parler, chacun trouve sa propre manière la meilleure et la plus belle, et comme celle qui est la mienne ici n'est pas semblable à la vôtre, de grâce ne la méprisez pas et n'en dites pas de mal. Si vous n'en êtes pas content, faites selon votre façon et conformément aux modes qu'on use et suit dans votre pays. Car je n'en serai pas jaloux et ne m'en montrerai pas offensé.

Pour Axular les difficultés à trouver un registre de langue littéraire adéquate s'expliquent par l'absence de tradition écrite et c'est en développant l'écrit basque, et en variant les expériences et la production, qu'il estime que la langue pourra s'enrichir et acquérir un prestige social :

Orai badirudi euscarac ahalque dela, arrotz dela, eztela iend'artean ausart, entregu, bithore eta ez trebe. Ceren are bere herricoen artean ere, ezpaitaquite batçuec, nola esquiriba, eta ez nola iracur.

Baldin eguin baliz euscaraz hanbat liburu, nola eguin baita latinez, franceses, edo bertce erdaraz eta hitzcuntçaz, hec beçain aberats eta complitu içanen cen euscara ere, eta baldin hala ez pada, euscaldunec berèc dute falta eta ez euscarac. (Axular, Guero, Iracurtçailleari)

Il semble aujourd'hui que le basque soit timoré et inexpérimenté, qu'il n'est pas audacieux, assuré, compétent, ni exercé en public. Car, même parmi ses locuteurs, certains ignorent comment l'écrire et le lire.

S'il avait été écrit autant de livres en basque qu'il en a été fait en latin, en français ou dans d'autres idiomes étrangers et langues, le basque aurait été aussi riche et accompli que ces langues, et s'il n'en est pas ainsi, la faute en revient aux Basques, et non à la langue basque.

Cette attitude critique d'Axular à l'égard de ses compatriotes sera l'objet d'une réplique de Tartas dans son prologue de Onsa hilceco bidia. Ce dernier, s'il avoue avoir utilisé surtout le basque mixain d'Aroue, très proche du souletin, indique toutefois y avoir introduit des éléments des autres dialectes (des provinces du nord) :

Ené euscara eta lengagia eztaquit aprobatia içanen denéz, bai, ala ez, Badu orotaric cerbait, çuberoac, Bassanauarrec, eta lapurdic emandrauco çerbait, baina ez oro; arueneguin dut neuré pieça pobria, hanco lengagia ezpada asqui eder, hanco euscarac, du oguena, eta ez euscaldunac. (Tartas, Onsa hilçeco bidia, Iraccurtçaliari) 
J'ignore si mon basque et mon langage sera ou non approuvé. Il tient quelque trait de partout; la Soule, la Basse-Navarre et le Labourd lui ont donné quelque chose, mais point tout. J'ai écrit ma pauvre pièce à Aroue. Si la langue du lieu n'est pas assez belle, la faute en revient au basque de l'endroit, et non au locuteur.

La plupart des auteurs recourent également au topos de la modestie sur cette question linguistique, utilisant divers arguments convenus. Le premier consiste à invoquer l'absence ou le peu de tradition antérieure, ainsi que Dechepare en plaçant à la fin de ses poèmes une citation latine d'Ouide : Debile principium melior fortuna sequatur. Liçarrague se fait l'écho dans son avis aux Basques de la difficulté à ouvrir la route en évoquant les imperfections de sa traduction :

... eta badaquigu ecen demborarequin anhitz hitz eta minçatzeco manera, eridenen dela obra hunetan bercera hobequi erran çatenic : halacoetan, gauçá ceren den daquitenetaric batbedera, orhoituren da, othoi, ecen hunelaco gauçác, guciz lengoage oraino vsatu gabe batetan, ecin behingoaz halaco perfectionetan iar daitezquela, nola behar bailiçateque. (Liçarrague, Testamentu berria, Heuscalduney)

... et nous savons qu'avec le temps on trouvera dans cette œuvre beaucoup de mots et de manières de dire que l'on aurait pu mieux exprimer autrement : dans de tels cas, chacun se souviendra, de grâce, puisqu'il s'agit de ces choses que l'on sait, que ces entreprises la première fois ne peuvent atteindre la perfection ainsi qu'il le faudrait, en particulier dans une langue encore non usitée.

Le même argument se rencontre chez Etcheberri de Ciboure dans son avis au dévot au sujet de la manière de son Manuel, où, plus qu'à la langue elle-même, il est fait référence à la mise en vers de la doctrine :

Guehiago ahal beçain humilqui aut othoizten,

Obratcho hau mespreçia gogorqui ezteçaquen.

Hafteac gaitçac direla errana duc communqui

Hunen gañean eguinen dic cembait berçec hobequi

(Etcheberri de Ciboure, Iracurtçaile devotari eguilleac)

Encore plus : je te supplie très humblement

De ne point mépriser trop durement cette petite œuvre.

Il est dit communément que les débuts sont difficiles,

A partir de cet essai, quelqu'un d'autre fera mieux.

Autre thème classique dans le traitement du topos de l'humilité repris par Liçarrague : l'idée que la faiblesse de l'expression ne doit pas masquer l'importance du propos qui dépasse l'auteur :

guciagatic-ere minçatzeco manerán anhitz arrastatu gabe, Iaincoaren hitz purari iarreiquiteco desira dutenéc, sporçu dugu eridenen dutela (suporturequin) cerçaz contenta. (Liçarrague, Heuscalduney)

Malgré tout, nous sommes confiant que sans s'arrêter beaucoup à la manière de parler, ceux qui ont le désir se suivre la pure parole de Dieu trouveront (en exerçant leur patience) leur contentement.

Ce thème est également présent chez Etcheberri de Ciboure dans son avis au dévot : 
Manuala eman diat, den beçala coplaca.

Bañan nihorc eztemala beharria hitçera,

Hambat nola hitz azpian ehorçia denera.

(Etcheberri de Ciboure, Manual devotionezcoa, Iracurtçaile devotari eguilleac)

J'ai mis en couplets le Manuel tel qu'il est.

Mais que nul ne prête l'oreille aux mots

Autant qu'il le fait à ce qui est enfoui sous eux.

Un autre propos conventionnel que l'on rencontre dans divers prologues basques consiste à présenter l'ouvrage comme un essai dont on espère qu'il sera amélioré. Les formulations peuvent varier. Dechepare, dans sa dédicace, indiquait avoir aussi fait imprimer son livre afin que ceux qui viendront par la suite aient davantage de raison pour le faire progresser [l'euskara]. Liçarrague, quant à lui, manifestait son espoir d'avoir l'occasion, après avoir fait la preuve que le basque permettait une traduction aussi délicate et difficile, d'améliorer lui-même, avec ses collaborateurs, sa traduction par la suite :

Eta baldin sperança dugun beçala, oraindrano eguin den hunetán heuscaldunac goçoric edo edificationeric hartzen badu, hunetan emplegatu içan diradenéc bihotz harturen duté, oraindanic gogo-ere duten beçala, eguin denaren berriz ikusteco eta corrigitzeco : bayeta, baldin Iaunac hala placer badu, passage difficilenén declaragarri annotationén eçarteco. (Liçarrague, Heuscalduney)

Et si, comme nous l'espérons, le Basque trouve du plaisir et quelque édification dans cette traduction faite à ce jour, ceux qui l'ont réalisée prendront courage pour corriger et revoir, comme ils en ont déjà l'intention, ce qui a été fait : et aussi, si cela plait à Dieu, pour établir des annotations éclairant les passages les plus difficiles.

Cette idée est formulée par Materre et Axular sur un ton plus polémique :

Eta Saraco Euscara hunetcaz content eztenac ezquiriba beça bertce Euscara hobeago batez eta hobequiago, ez-naiz ni hargatic bekaiztuco, eta ez imbidios içanen. (Materre, Dotrina christiana, Euscaldunei)

Et que celui qui n'est pas satisfait de ce basque de Sare écrive mieux et dans un basque meilleur, cela ne me rendra ni jaloux ni envieux.

Aitcitic haur da nic nahi nuqueyen gaucetaric bat, ene enseiu appur hunec quilica cinitçan eta guticia, enseiu hobeago baten eguitera eta ene hemengo falten ere erremediatcera. Ceren halatan, ez liçateque euscara hain labur, escas eta ez hertsi, nola munduac vste baitu, eta baitaduca, dela. (Axular, Guero, Iracurtçailleari)

Au contraire l'une des choses que je souhaiterais est que ce petit essai vous incite et vous motive à faire un autre essai meilleur que celui-ci et à corriger les fautes commises par moi ici. Car si l'on avait procédé ainsi, le basque ne serait pas aussi limité et pauvre, ni aussi étriqué, que le monde croit et tient qu'il est.

Enfin, dernier thème rencontré dans certains prologues, parfois par le biais linguistique, celui du lectorat. Il n'est pas rare en effet que le prologuiste précise pour qui particulièrement il a rédigé son ouvrage. Dans les prologues basques ce point apparaît de diverses manières, les définitions du lectorat suggérées par les auteurs pouvant être d'ordre proprement linguistique, littéraire, ou social.

La délimitation d'ordre linguistique apparaît comme une justification du choix de langue. Materre et Axular notamment font chacun une remarque générale, préfigurant l'évolution postérieure de la production littéraire basque : leur ouvrage est destiné principalement, du moins est-il ainsi présenté, aux lecteurs ne sachant que le basque. Dans l'avis au lecteur de la seconde édition, Materre indique ainsi à propos de la troisième partie de sa doctrine : 
Eta ceren añhitz baita Euskal-herrian iracurtcen daquienic, baiña ez Euskara baicen bertce hitzcunçaric aditcen, halatan eguin ditut halacoenzat Euscaraz debocinozko othoitz eta Oracino batçuc, goicetan, arratsetan, eta bertce añhitz denboratan eta ocasinotan eguin eta erran ahal ditezqueyenac, ceinetçaz eguiten baitut hirurgarren partea. (Materre, Dotrina christiana, Iracvrcailleari).

Et comme il y a beaucoup de gens au Pays Basque qui savent lire, mais qui n'entendent d'autre langue que le basque, j'ai écrit pour eux en basque des oraisons et des prières de dévotion que l'on peut dire le matin, le soir, et en beaucoup de moments et d'occasions, et avec lesquels j'ai composé une troisième partie.

Axular indique également dans le passage de son prologue cité plus haut que le projet initial était de rédiger un ouvrage de morale religieuse à l'intention surtout des lecteurs ne connaissant pas d'autre langue (Eta on çatequeiela, gauça hunetçaz liburu baten, euscaraz, guztiz ere euscararic baicen etciaquitenentçat, eguitea).

Chez Etxeberri de Sare cette question est abordée par le biais du genre littéraire. En effet, invoquant l'exemple des Grecs dans l'Antiquité, il rédige son ouvrage en vers, car il est destiné à une nation aimant les chants :

Gviristiñoa, eman diat escarazco versutan,

Catholico manuala neure asti ordutan

Ikhussiric nola bainaiz iaiatcez escalduna

Gure natioa dela copla maite duena.

Hartaracotz iaquiara diat versus eçarri,

Lasterrago ikhas eta maizago aipha garri.

Lehenago nonbait vrrun Greçiaco partetan

Herrico legueac eman ohi ituen cantetan

Nola cantac maiz baitire munducoen ahoan,

Hala cantez orhoituric, maiz çitusten gogoan,

Hequin bada costuma onaz orhoituric lerroca

Manuala eman diat, den beçala coplaca.

(Etcheberri, Manual devotionezcoa, Iracvrtcaille devotari egvilleac)

Chrétien, j'ai écrit en vers basques,

Le manuel catholique durant mon temps de loisir,

Ayant observé, étant basque de naissance,

Que notre nation aime les couplets.

Pour cette raison délibérément je l'ai mis en vers

Afin qu'il soit plus vite appris, et plus souvent mentionné.

Jadis quelque part au loin dans les contrées de Grèce

Les lois du pays étaient mises en couplets :

Comme les chants viennent souvent aux lèvres des gens,

Ainsi, en se souvenant de ceux-ci, ils avaient les lois fréquemment à l'esprit.

Me rappelant donc de leur bonne coutume, ligne à ligne,

J'ai mis en couplets le Manuel tel qu'il est.

Le statut social des lecteurs, ou d'une partie de ceux-ci, est mentionné de façon récurrente au $\mathrm{XVII}^{\mathrm{e}}$ siècle en Labourd, à propos des gens de mer (lesquels par la suite disparaîtront comme destinataires spécifiques des textes basques). Certains auteurs y font référence de manière explicite dans le corps de leur texte comme par exemple Materre ${ }^{26}$ ou Haramboure, d'autres, comme Gasteluçar, dans leur prologue général. Quant à Etcheberri, il offre un avis particulier au sein du second livre de son Manuel : Avis au marin lecteur (Itsasturi iracvrtzailleari abi$s u a)^{27}$. Vers intéressants dans lesquels l'auteur souligne la nature aventureuse de l'activité tant du point de vue physique que financier : 
Mariñelen emazteac goicean tuc senhardun,

Eta titcha aldaturic, arratsean alhargun.

Orain aberatz burgessa, aurkhi moian gabea,

Ceren vreco ona den haicearen parea.

(Etcheberri, Manual devotionezcoa, Itsasturi iracvurtzailleari abisva)

Les femmes de marins ont époux le matin,

Et, le sort ayant changé, sont veuves le soir.

Maintenant bourgeois riche, bientôt sans ressources,

Car le bien de la mer est semblable au vent

Enfin, dans quelques prologues des ouvrages destinés à l'enseignement le destinataire spécifique (membres du clergé et enseignants) est précisé comme chez Liçarrague ou Belapeyre.

\section{Les prologues diglossiques}

Parmi les ouvrages mentionnés, deux ont un prologue qui n'est ni rédigé en basque, ni même traduit : il s'agit d'une part du prologue de Beriayn (1621), et d'autre part de celui d'Oihenart (1656) en tête de ses poèmes.

Ainsi qu'on l'a dit plus haut, les prologues et avis au lecteur des ouvrages basques des $\mathrm{XVI}^{\circ}$ et $\mathrm{XVII}{ }^{\circ}$ siècles, contrairement à certaines dédicaces, sont toujours rédigés en basque. Cela n'est pas étonnant puisque l'un des motifs invoqués par les auteurs dans leur prologue pour expliquer le choix de langue consiste à alléguer qu'ils rendent service aux lecteurs ne connaissant que le basque (Materre, Axular), ou aimant particulièrement les vers basques chantés (Etcheberri de Ciboure, Gasteluçar).

Pourquoi donc les ouvrages de Beriayn et Oihenart ne suivent pas cette voie? Pour deux raisons distinctes, mais qui toutes deux mettent en évidence la situation sociolinguistique en Haute-Navarre d'une part, dans les provinces rattachées à la Couronne de France d'autre part.

L'ouvrage de Beriayn est un ouvrage pratique : un guide pour entendre la messe, rédigé en castillan et basque, les deux langues de l'évêché de Pampelune, comme il est dit dans le titre même de l'ouvrage (Tratado de como se ha de oyr missa, escrito en Romance, y Bascuence, lenguages de este Obispado de Pamplona). L'ouvrage étant bilingue, on attend également un prologue bilingue, mais tel n'est pas le cas : seul le texte espagnol de l'avis au lecteur est publié (il en est de même pour les autres paratextes, y compris le titre, et la table des matières). Ceci traduit sans aucun doute la place secondaire occupée par le basque dans les zones où le basque était présent en Navarre au début du $\mathrm{XVII}{ }^{\circ}$ siècle, tandis qu'à la suite du Concile de Trente un effort particulier a été entrepris par l'Evêché pour utiliser les langues vulgaires dans la formation religieuse des populations (Jimeno Jurio, 1998).

Dans son avis au lecteur, Beriayn évoque la question dialectale et il montre la perception que l'on pouvait avoir en Navarre de cette question. Selon lui le dialecte standard des Basques de Haute-Navarre est celui de Pampelune, à la fois parce qu'il est le plus répandu et celui qui est le plus connu :

Escriuo en Romance, y bascuence lenguages deste Obispado, y aunque en diferentes partes del ay en algunas cosas, diuersos modos de hablar, yo escriuo el que se habla en Pamplona, Cabeça deste Reyno, y obispado de Nauarra, que es el que se 
habla en la mayor parte del, donde se habla bascuence, y el que mejor se entiende en todas las partes. (Beriayn, Tratado de como se ha de oyr missa, Al lector)

Mais la situation de diglossie influence les modes de gestion de la variété dialectale. A ceux pour lesquels le basque de Pampelune s'avérerait difficile à comprendre, Beriayn recommande de recourir au texte castillan :

$Y$ cuando a alguno le pareciere que en algunas cosas no se entiende, delo que escriuo en Romance se puede sacar el bascuence que se se usa en su tierra. (Beriayn, Tratado de como se ha de oyr missa, Al lector)

Le recours à la langue partenaire de diglossie comme langue des paratextes, c'est-à-dire comme métalangue, se rencontre aussi chez Oihenart. L'ouvrage d'Oihenart de 1657, en effet, bien que partiellement bilingue dans son contenu (les proverbes basques étant traduits en français, mais pas les poèmes), a pratiquement tous ses paratextes en français uniquement ${ }^{28}$ : titre de couverture, préface générale, glossaire, avis au lecteur précédant les poèmes, liste des fautes d'impression.

Particulièrement significatif est à cet égard le glossaire qui figure à la fin des poèmes. Contrairement à Liçarrague qui près d'un siècle plus tôt traduisait les termes labourdins en souletin, Oihenart traduit en français les vocables dont il craint qu'en raison de la variété dialectale ils ne seront pas partout compris ${ }^{29}$. Les explications qu'Oihenart donne de son attitude en tête de son glossaire explicitent dans un registre plus savant la démarche de Beriayn :

Le peu de communication que les trois Prouinces du païs de Basques, qui sont deça les Monts Pyrenées, (à sçavoir Labourt, Basse-Nauarre \& Soule) ont entre-elles, dautant qu'elles dépendent de diuers Gouuernemens, \& de diuers ressorts de Iustice, est cause de ce que plusieurs mots anciens Basques, qui se sont conseruez en chacune de ces Prouinces, ne sont pas entendus en l'autre. C'est ce qui m'a obligé à mettre icy l'explication de quelques mots de cette sorte, qui se trouuent dans ce Recueil de Vers. (Oihenart, Explication des mots rares qui se rencontrent parmi les vers)

\section{Les premières préfaces modernes}

Au cours de la seconde moitié du $\mathrm{XVII}^{\circ}$ siècle, une modification des conventions en matière de prologues auctoriaux apparaît : la place de l'interpersonnel diminue sensiblement, au profit d'un développement thématique et de ce que Genette (1987: 184) appelle la valorisation du texte. Dans les textes basques, un équivalent d'emprunt au terme préface apparaît, tel que prefacioa, bien que abisu et les formes datives nues ne soient pas abandonnés.

Parmi les textes du corpus, celui qui manifeste le premier un tel changement, bien qu'il conserve encore un caractère interpersonnel marqué, est celui d'Argaiñaratz (1665). ${ }^{30}$

L'adresse aux dévots (Devotei) d'Argaiñaratz dans son Devoten brebiarioa, qui n'a été conservé, semble-t-il, que par une copie manuscrite de médiocre qualité (voir annexe) est essentiellement une présentation de l'iconographie de l'ouvrage. Cette dernière, qui reflète la structure de la première partie du livre, n'a pu être conservée dans sa totalité, puisque deux seulement des sept gravures devant y figurer étaient encore conservées dans le seul exemplaire de l'ouvrage retrouvé par Vinson. 
Du point de vue de l'étude des prologues, cette adresse offre la particularité de commenter l'image d'une image. Le lecteur, en effet, est appelé à considérer le bréviaire de la même manière que les saintes de l'ouvrage sont représentées dans sept gravures comme s'inspirant dans leur vies de pieux tableaux qu'elles gardaient devant leurs yeux.

Ainsi le lecteur est-il encouragé, en même temps qu'il lit les textes de dévotion (en vers) ${ }^{31}$ du bréviaire, à méditer, à chacun des sept moments de la journées signalés pour la prière (Matines, Prime, Terce, etc), sur chacune des saintes représentées dans les gravures et à considérer par exemple :

Vesperetan. Sant Helena, ceina bere hill orenaren contemplatcen baitcen bethi occupatua, huntaracotz beguien aitcinean çaducala errethaula bat ceiñetan aingueru batec erhiaz beçala eracusten baitcioen erroloia [texte de Vinson : erroloio] baten marcan bere bicia, hiltceraco vesperan çuela, haren errethaulan agueri den beçala. (Argaiñaratz, Devoten breviarioa, Devotei)

Aux Vêpres, sainte Hélène, laquelle était toujours occupée à contempler l'heure de sa mort, tenant pour cela devant ses yeux un tableau où, à la veille de sa mort, un ange lui montrait, comme avec le doigt, dans la marque d'une horloge, sa vie, ainsi que vous le verrez dans sa gravure.

Les gravures représentent uniquement des femmes, ce qui néanmoins ne semble pas indiquer un ouvrage spécialement orienté vers un lectorat féminin; rien, en tout cas, ne l'indique dans le prologue, ni dans les vers. Vinson, qui pour cette raison n'avait pas traduit le titre Bréviaire des dévotes, observe dans l'avertissement de son édition que les livres basques illustrés antérieurs au XIXé sont fort peu nombreux, et que la matière du livre, y compris bien sûr les gravures, ont leur probable origine dans quelque ouvrage français : les noms propres des princesses sont visiblement pris du français (par exemple, Lorrenaco Margarita Alençõgo duqueça), et l'une des deux gravures préservées avait conservé le mot prime.

La préface (Prefacioa) de Gasteluçar (1686), est également écrite en prose, alors que l'ouvrage, en dehors de quelques litanies, psaumes et prières, est en vers. L'interpersonnalité est pratiquement absente : l'usage de la deuxième personne indiquant l'adresse en discours direct au lecteur y est abandonné, et l'auteur est à peine entraperçu au détour d'une forme verbale. Cette préface vient doubler l'avertissement au lecteur ${ }^{32}$; ils forment donc deux textes séparés, sans que ce doublement corresponde à une division thématique de l'ouvrage, comme cela est le cas chez Oihenart (1657).

La préface est pour l'essentiel constituée d'une exhortation à la vie dévote et à l'abandon des plaisirs et ambitions de ce monde, dans ce qui apparaît comme une véritable introduction au corps de l'ouvrage, plus que comme un texte extérieur à celui-ci.

L'avertissement au lecteur (Abisua) conserve, lui, certains des éléments des autres prologues des textes basques examinés précédemment, en particulier l'indication du plan (titre des sept parties de l'ouvrage) et des circonstances expliquant pourquoi, et à l'intention de quel public, l'auteur a réalisé son ouvrage :

Denbora hautan, hañitzek hañitz liburu eder argira eman tuste; ezta, bada, hau bertzeak baño ederragoa; bañan nola berze gauzetan bezala, debozionean gustu diferenteak baitire, iduritu zait hañitz deboten artean, batzuek huntan gustu hartuko dutela, gustiz mariñel debotek; eta hek prinzipalki konsideraturik, deliberatu dut liburu hunen egitera. (Gasteluçar, Eguia catolicac, Abisua) 
Ces temps-ci, beaucoup ont publié beaucoup de beaux livres, celui n'est pas plus beau que les autres; mais comme il existe des goûts différents en matière de dévotion ainsi que dans les autres choses, il m'a semblé que, parmi de nombreux dévots, certains, en particulier les marins dévots, l'apprécieront. C'est en tenant compte principalement de ces derniers, que j'ai décidé d'écrire ce livre.

Un cas apparemment semblable de doublement des prologues auctoriaux est celui de l'ouvrage d'Oihenart (1657) qui contient lui aussi une préface et un avertissement au lecteur, tous deux en français comme indiqué précédemment. Mais en ce cas les deux prologues correspondent aux deux parties, bien distinctes, de l'ouvrage : la préface ayant été rédigée pour être placée en tête du recueil de proverbes, et l'avertissement en tête des poèmes.

La préface aux dictons développe deux points de nature différente : l'un qui relève de la valorisation thématique; l'autre qui concerne l'orthographe. Le premier point est traité de manière relativement impersonnelle bien que l'auteur indique avoir voulu rendre service à [sa] Patrie, en rendant plus familiers et perdurables par le moyen de l'impression les proverbes que dès [son] jeune âge il avait recueillis de la bouche du peuple. Malgré cette note, nous sommes loin des petites scénettes esquissées en introduction des prologues d'Axular et Tartas. D'ailleurs, s'agissant d'un recueil de proverbes, l'auteur ne se présente pas comme un véritable auteur, et il n'entend pas se donner ce statut aux yeux du lecteur. Il limite tout au plus son intervention à la sélection des dictons, que celle-ci soit volontaire (I'en ay omis quelques-uns, qui sont vulgaires, pour n'y auoir pas remarqué le caractère, ny les marques des veritables Prouerbes) ou involontaire (Ie veux croire qu'il en reste beaucoup qui ne sont pas venus à ma connoissance, particulièrement de ceux qui sont en vsage parmy les Basques de delà les montsPyrennées, avec lesquels ie n'ay pas eu que fort peu de communication).

Quant aux remarques orthographiques, elles représentent un embryon de phonologie comparative : Oihenart, précurseur de la bascologie, est le seul auteur à accorder une telle importance à cette question, qu'il traite de façon originale, inventant sa propre graphie, fondée sur un usage particulier de diacritiques (que l'imprimeur ne sera pas en mesure de respecter, et qui restera donc très théorique, puisque non appliquée et demeurée sans suite).

Cette situation se retrouve dans l'avertissement au lecteur précédant les poèmes : nous sommes en effet à nouveau en présence d'un texte en forme de traité technique, non plus d'orthographe, mais de versification. L'auteur, qui propose d'adapter le modèle classique à la versification basque, voit dans ses vers l'illustration de cette ambition, et c'est dans cela qu'il situe le mérite de ses poésies, non dans leur contenu. C'est d'une certaine façon l'attitude inverse de celle adoptée par La Fontaine, lequel dans le prologue de ses Fables indiquait que ce n'est pas tant par la forme que j'ai donnée à cet ouvrage qu'on en doit mesurer le prix, que par son utilité et sa matière. Oihenart, au contraire, entend signaler au lecteur que c'est dans la forme des vers que son essai trouve sa raison d'être principale :

C'est ce qui m'a obligé, apres auoir parlé des ces Regles en vn autre Ouurage, à souffrir que ce peu de Vers, qui m'estoient échappez en mon jeune âge, voye le iour, afin qu'il apparoisse, que la pratique de ces Regles n'est pas si mal aisée en nostre Langue, qu'aucuns se sont persuadez, \& non point pour autre sujet; Car comme en les composant ie n'auois cherché que mon diuertissement. (Oihenart, Av lectevr) 
Oihenart, au demeurant, ne prétend pas être un bon poète :

Aussi ne pretens-je pas, par la publication qui s'en fera, participer à l'honneur qui accompagne les Ouurages des bons Poëtes. (Oihenart, Av lectevr)

\section{Les prologues multipliés d'Etcheberri de Ciboure}

Pour conclure cette présentation, nous évoquerons brièvement le cas le plus original dans le contexte basque : celui d'Etcheberri de Ciboure, lequel, dans son Manual devotionezcoa (1627/1669), propose en fait plusieurs prologues, selon une méthode d'ailleurs attestée dans les littératures voisines (Cayuela : 217). De plus, s'agissant d'un manuel en vers, tous ces prologues ont eux-mêmes de cette forme et composés de distiques en vers de 15 pieds $(8+7)$, à rime alternée.

Il y a en tout cinq prologues généraux : trois en tête de l'ouvrage, relatifs respectivement au théme, à la forme, et à la composition de l'ouvrage, et un en tête des deux livres composant le manuel, à savoir d'une part le catéchisme et d'autre part les prières. ${ }^{33}$

Le premier des trois prologues du livre entier est destiné à souligner l'importance de l'ouvrage et se veut une exhortation à l'apprendrẹ, car il s'agit d'un catéchisme et de prières (Manualaren ikhastera iraţ̧armendua); le second est une présentation de la contribution personnelle de l'auteur, laquelle a consisté à la mise en couplets destinés à être chantés de prières du manuel (Iracurtçaille devotari eguilleac liburu hunen maneraz); le troisième indique la composition de l'ouvrage en livres eux-mêmes divisés chacun en deux parties (Liburuaren errepartimenduaz). Point remarquable, aucun de ces prologues ne traite de la question de la langue proprement dite, bien qu'elle ait été semble-t-il l'objet de polémiques (cf. supra et la préface d'Altuna à l'édition de 1981).

Dans le second prologue, que nous avons rapporté plus haut dans sa plus grande partie, l'auteur explique les raisons pour lesquelles il a composé son ouvrage en vers (cf. supra). Mitxelena (1981) fonde sur ses indications l'hypothèse selon laquelle, contrairement à Axular, Etcheberri avait écrit ses vers pour un public qui ne lisait pas, afin de lui en faciliter l'apprentissage. Les objectifs prosaïques d'Etcheberri avaient été évoqués déjà par Oihenart dans son Art poétique basque : Ie lui ay ouy dire au temps qu'il composoit ses Vers qu'il trauaillait principalement pour les mariniers Lesquels les Chantoint sur la mer; Ce qui faict Iuger qu'il Escriuoit plus tost par Un motif de Charitté que par aucune ambition, ou Vainegloire, Et quil auoit le zèle de profiter à son prochain que doit avoir Un Veritable Ecclesiastique. Ce n'est pas le lieu d'examiner l'œuvre d'Etcheberri, mais je reste pour ma part dubitatif, malgré l'autorité des auteurs mentionnés, l'un à titre d'analyste, le second en tant que rapporteur des propos de l'auteur, sur l'exactitude de cette interprétation. La versification d'Etcheberri, même dans le second livre du Manual qui est considéré comme littérairement plus modeste (Altuna, dans son édition du $1^{\text {c }}$ livre de 1981, Mitxelena 1981), n'est certainement pas celle que l'on attendrait de textes destinés à être mémorisés facilement : les inversions, avec antéposition des syntagmes adnominaux ou adjectivaux au vers précédent, de manière à obtenir la rime, abondent, comme si le basque était du latin. Ces licences poétiques qu'Oihenart jugeait lui-même exhorbitantes en basque ne correspondent guère aux objectifs mentionnés : que l'on ait réellement appris la doctrine catholique sur les vers d'Etcheberri, même chantés, serait sur- 
prenant. Certes les vers d'Etcheberri ont eu un grand succès populaire, et certains de ses cantiques (notamment de Noelak) se chantent encore dans les églises du Pays Basque. De même, la nature pédagogique de l'ouvrage est incontestable, et son titre même l'indique. Pour autant il me semble difficile de ne pas prêter à l'auteur une ambition allant au-delà d'une mise en couplets simplement destinée à faciliter la mémorisation chez un public analphabète ${ }^{34}$. Mais laissons ici ce débat, qui mériterait un examen plus approfondi de l'œuvre d'Etcheberri.

Le prologue précédant le premier livre consacré à la doctrine est un avis au lecteur (Iracurtçailleari abisua) thématique, formé de vingt et un distiques, expliquant au lecteur la nécessité pour lui de se conformer à un mode de vie chrétien. Le prologue joint au second livre, lequel présente les prières, est composé de neuf distiques.

Cette idée de faire précéder les parties internes d'un ouvrage d'un prologue et même, dans le cas du Manuel de dévotion d'Etcheberri, d'une dédicace ${ }^{35}$, est inédite dans les textes basques, mais on en trouve des exemples ailleurs. Cayuela (1996 : 217) signale que dans ses Rumbos peligrosos, ouvrage publié à Anvers en 1683 , J. Penso de la Vega procède ainsi pour chacune des nouvelles incluses dans son ouvrage.

Il est vrai que le cas du Manuel de dévotion est particulier eu égard à la nature de l'ouvrage. Si la disposition matérielle et les sous-titres n'étaient là, il serait difficile sans doute de repérer comme paratextes ces prologues internes. D'ailleurs il y a bien d'autres passages qui pourraient relever d'une telle sélection, en particulier dans le second livre, consacré aux prières, comme par exemple l'avis au lecteur marin évoqué plus haut. L'auteur présente ces prières comme destinées à être apprises par cœur (Mes peines auront été assez récompensées / Si durant tes loisirs tu veux les apprendre); cf. Mitxelena 1981, et ici même la note 34. Elle sont donc à la première personne, et adressées en discours direct à Dieu, ce que dans son avis interne de ce second livre Etcheberri exprime ainsi : Ecen othoitcen han diat moldea arrimatu, / Eta Iancoari mintço natçaiola, moldatu (litt. Car là, des prières, j'ai placé la méthode, et l'ai composée en m'adressant à Dieu).

Si le lecteur virtuel est la référence construite de la première personne des prières qu'il est supposé apprendre et s'approprier, tous les passages explicatifs figurant entre celles-ci apparaissent à la manière de paratextes où l'auteur s'adresse au lecteur pour lui dire comment il lui faut interpréter, comprendre ou dire les prières; d'ailleurs Etcheberri utilise fréquemment le mot abisua pour désigner ces éclaircissements dans ces intertitres, comme dans l'avis au lecteur marin. On retrouve alors dans le corps du texte le je auctorial et le vous du lecteur allocutaire, classique des prologues des $\mathrm{XVI}^{\circ}$ et $\mathrm{XVII}{ }^{\circ}$ siècles. 


\section{Notes}

1. Bien qu'elle concerne un texte datant d'une période située au-delà de celle à laquelle se limite cette étude, il faudrait citer comme une exception la présentation de Mitxelena (1963) du prologue -original à bien des égards dans le contexte basque- d'un écrit manuscrit (1782) d'Eguiateguy. En effet cette brève étude, destinée à faire connaître alors un manuscrit inconnu, en attendant sa publication, représente désormais la seule information disponible regardant son contenu. Cet essai d'économie domestique, intitulé Aberatstarzün güzien giltz bakhoitza [La clé unique de toutes les richesses], et que A. Irigaray fit acquérir, semble-t-il, par la Bibliothèque de la Diputación du Guipuscoa (cf. la préface de T. Peillen à l'édition (1983) de Lehen liburia edo filosofo huskaldunaren ekheia (1785)), ne s'y trouve plus.

2. Je ne tiens pas compte ici des éléments d'intertextualité, et notamment des citations et des récits restitués, qui tiennent parfois une place importante dans les ouvrages de cette époque, y compris dans les ouvrages basques tels que ceux d'Axular ou Tartas. J'écarte également les appendices expliquant les références historiques, géographiques, littéraires ou autres des textes. Ces derniers ne se rencontrent guère dans les textes basques (celles que l'on trouve chez Liçarrague à propos des termes bibliques sont traduites).

3. Le regroupement des prologues des auteurs et des traducteurs dans le cas des textes basques s'explique par le poids des considérations linguistiques. Genette (1987:243, note 2) fait justement remarquer que si la préface rédigée par un traducteur se présente en principe comme une préface ultérieure allographe, lorsque le traducteur prologuiste commente sa propre traduction (ce qui est d'ordinaire le cas dans les textes basques), son texte cesse d'être allographe. C'est la raison pour laquelle, à mon sens, l'adresse aux Basques de Liçarrague devait être prise en compte ici à côté de celle des autres auteurs de notre corpus.

\section{Texte cité selon l'édition révisée et actualisée de M. de Riquer (1980).}

5. En fait l'ouvrage de B. Dechepare contient quelques lignes que l'on pourrait marginalement considérer comme représentant un avertissement au lecteur et à l'imprimeur. Elles sont sans titre, rédigées en latin (Aduertant Impressor, et lectores quod...), et précèdent sur une page à part la dédicace. Elles visent à indiquer la prononciation de certaines lettres consonnes $(z, t$ devant $i$ et et $c$ devant $a, o, u)$

6. Je ne tiendrai pas compte des prologues des textes non destinés à un lectorat bascophone, en particulier l'Interprect Ou traduction du François Espagnol \& Basque (publié vers 1620 par Voltoire), et qui est destiné aux personnes désirant apprendre la basque. Ce dernier contient un avis en français intitulé $\mathrm{Au}$ lecteur salut.

7. Par rapport aux indications de la bibliographie de Vinson, les avertissements ou prologues de l'auteur que je n'ai pu consulter sont : i) une adresse aux Messieurs basques (Iavn escaldvney) de Pouvreau dans sa traduction (1656) de la Doctrine chrétienne de Richelieu; ii) encore de Pouvreau, une adresse au lecteur en basque puis en français dans sa traduction (1665) du Combattimento spirituale de Lorenzo Scrupoli; iii) l'avis au lecteur (iracvurţ̧ailleari abissua) d'Arambillaga dans la traduction (1684) de 1'Imitation de Jesus-Christ. Troisième livre (Jesu Christoren imitationea. Hirvgarren libvrva).

Je ne prends en compte que les seuls textes des auteurs ou traducteurs eux-mêmes, et donc ni les préfaces traduites, comme l'advertissement de Liçarrague ou la préface de Philotea de Pouvreau, ni les prologues allographes, telle que, par exemple, la préface de Harizmendi au Debocino eskuarra de Haramboure. Il va sans dire, par ailleurs, que cette étude exclut les paratextes créés par les éditeurs postérieurs (par exemple l'adresse aux Basques de Vinson, rédigée en basque, contrairement à l'avertissement à caractère technique et savant, en tête de son édition (1910) du Bréviaire des dévots d'Argaiñaratz). Je n'examinerai pas non plus les prologues de Belapeyre (1696) qui ont un caractère institutionnel marqué. Il s'agit de deux adresses en forme de recommandations destinées en particulier aux curés et prêtres de Soule, l'une $(20 / 10 / 1695)$ en tête de la première partie, l'autre (2/04/1696) en tête de la seconde. Louvrage de Belapeyre, qui fut réalisé dans des conditions difficiles (cf. Agirre 1996), dispose par ailleurs d'autres textes préliminaires, importants pour la compréhension de cette période de l'histoire religieuse de la Soule, dont notamment d'une part, le texte d'une déclaration en français en date du 27/05/1693, où Belapeyre en tant qu'Official de l'Evêché d'Oloron en Soule, fixe les obligations des membres du clergé et celle des autorités publiques en matière d'éducation de la jeunesse, et d'autre part, une Imploration du bras séculier à Messieurs les Juges du Siège Royal de Licharre du 12 novembre 1695, traitant du même sujet ; cf. Oyarcabal 1999.

8. La datation double indique, d'une part que le seul texte qui a été conservé est celui de 1669 , mais que, d'autre part, les paratextes remontent certainement, dans leur substance, à la première édition. On a conservé cette dernière date dans la référence datée afin de mieux situer le texte dans la chronologie de la littérature labourdine (second texte connu après celui de Materre). 
9. Dans le cadre de la littérature basque cette contradiction est particulièrement évidente dans les prologues des pastorales souletines anciennes, lesquels régulièrement soulignent l'intérêt du sujet de la pastorale, mais finissent par des paroles d'excuses concernant l'imperfection de la représentation dramatique.

10. A vrai dire deux autres ouvrages pourraient être mentionnés : les catéchismes bilingues espagnolbasque d'Elso (1561) et de Betolaza (1596). Mais il est peu probable que Materre ait pu les consulter. Le premier, apparemment perdu, fut publié en Haute-Navarre, et le second à Bilbao.

11. De ce point de vue les ouvrages de Dechepare et Liçarrague (comme celui de Materre lui-même) pourraient donner une idée assez fausse de la fixation des normes de l'écriture basque à cette époque. Ces ouvrages, qui s'inspirent peu ou pas du tout les uns des autres, sont d'une très bonne tenue, mais ce n'est sans doute pas là l'expression ou le reflet d'une réalité sociale très répandue, plutôt le fruit d'efforts individuels réalisés par des personnalités singulières.

12. Cette phrase est fautive, la proposition déclarative n'étant pas régie : peut-être le verbe recteur a-t-il été omis. Je n'ai pu consulter la version originale de l'ouvrage, et j'ignore si le texte de l'édition d'Akesolo la restitue fidèlement.

13. L'emploi de heuscal herria (absent chez Dechepare, mais que l'on retrouve avec Materre, et bien sûr, ensuite, régulièrement), se fait dans l'adresse aux Basques, ainsi que dans le titre et dans le texte de l'avertissement précédant l'ABC, dans les trois cas le terme étant à l'inessif (heuscal herrian, rendu en français dans la dédicace par l'expression au pays des Basques). Pour la désignation ethnique, il utilise le dérivé heuscaldun.

14. Selon la dédicace de l'auteur à Sauvat d'Tharce, Evêque de Tarbes, il s'agit d'un ouvrage de commande (nik segur zure debozino sainduak debozinozko obra hunetan ni emplegatzeaz ohore handi bat errezibitu dut 'pour sûr, j'ai reçu un grand honneur du fait que votre sainte dévotion m'ait employé moi dans cette œuvre de dévotion'). Il fut lui aussi apparemment réalisé dans des conditions difficiles, peut-être en raison du choix fait par d'Tharce de l'auteur. En effet, dans un hommage rendu par à l'auteur en tête de l'ouvrage, Harizmendi écrit ces vers qui viennent peut-être en écho d'une polémique, à moins qu'il ne s'agisse ici également d'une allusion au conflit linguistique qui sera évoqué plus loin :

Badakhusat klarki, zuk egin liburuan,

Merezi hainitzak ditutzula zeruan :

Nahiz inbidiak, erran dezan zer nahi,

Merezi hek berdin eztakizketzu bahi.

Je vois clairement dans le livre que vous avez fait / Que vous avez de grands mérites au ciel / Quoi que les envieux disent / On ne peut vous ôter ces mérites.

15. Dans sa préface à son édition critique du ler livre du Manual d'Etcheberri, Altuna évoque le climat passablement envenimé de l'époque, que nous restituent les paratextes (autres que les prologues auctoriaux qui eux n'évoquent pas du tout la question, comme nous le verrons plus loin). Mais, concernant les envieux et adversaires qu'Etcheberri aurait pu avoir, il avance une autre hypothèse : celle d'une rivalité au sein du monde littéraire basque. Selon Altuna, il est peu probable que cette cabale ait été créée par les membres de ce qu'on désigne comme l'école de Sare, puisque certains d'entre eux, tel Axular, figuraient parmi les auteurs des approbations du Manual d'Etcheberri. Bref il ne croit pas à une jalousie entre deux écoles labourdines, et il suggère que c'est vers Oihenart qu'il faudrait se tourner pour identifier la source des critiques visant Etcheberri. Cependant, les arguments avancés, qui reposent sur la critique qu'Oihenart fera de la versification d'Etcheberri dans son Art poétique, ne me semblent pas convaincants.

$\begin{array}{ll}\text { 16. Je transcris ici ces vers de louanges (Laudoriozko koplak) selon l'édition d'Akes } & \text { Moi au moins, je reconnais } \\ \text { Nik behintzat aithortzen dut } & \text { que nous sommes votre débiteur, } \\ \text { zure zordun garela, } & \text { que c'est vous êtes la torche } \\ \text { gure ilhunbetik khentzeko } & \text { propre à nous sortir des ténèbres. } \\ \text { zuzia zu zarela. } & \text { Le basque, qui, vieilli, } \\ \text { Zaharturik zioana } & \text { allait tomber, } \\ \text { eskara erortzera, } & \text { entré dans la maison Etxeberri, } \\ \text { Etxeberrian sarthurik } & \text { va renaître. } \\ \text { berriz doa sortzera. } & \text { Les étrangers ne sachant pas le basque } \\ \text { Erdaldunak ahal doazke } & \text { peuvent s'en aller chacun dans son pays, } \\ \text { zein bere herritara, } & \text { s'étant résignés à ce qu'ils ne feront pas } \\ \text { gogat eginik, galduko } & \text { disparaître la langue basque. } \\ \text { eztutela eskara. } & \text { Celle qui, depuis longtemps, } \\ \text { Aspaldion zegoena } & \text { pour tous, était inférieure, } \\ \text { guztientzat azpiko } & \text { Etxeberri l'ayant relevée, } \\ \text { Etxeberrik altxaturik } & \end{array}$


gorena da iarriko.

Eskaldunak hel bekizkit

haren ohoratzera,

zeren eskara eman duen

erdararen gañera. se situera au plus haut.

Que les Basques viennent à moi

pour l'honorer,

car il a mis la langue basque

au dessus de l'erdara.

17. La notion de langue mélangée (si ce terme réfère bien chez Haramboure à celle d'un basque associant les particularités de divers dialectes) sera en quelque sorte revendiquée par Tartas (1666) qui dira avoir voulu utiliser un basque ayant orotarik zerbait 'quelque chose de partout', ainsi que nous le verrons plus loin dans le texte. Chez Liçarrague la démarche semble avoir été différente, puisque ce dernier revendiquait plutôt une langue dégagée des influences locales particulières.

18. Je ne tiens pas compte ici du catéchisme bilingue d'Ochoa de Capanaga paru une vingtaine d'années plus tard (1656), et présentant en regard du texte espagnol sa traduction en biscayen. On peut supposer que cet ouvrage n'eut guère d'échos en deçà de la Bidassoa.

19. Rappelons que, jusqu'à la Révolution, le Labourd et les deux-tiers occidentaux de la BasseNavarre relevaient de l'évêché de Bayonne, mais que la Soule était rattachée à l'évêché d'Oloron, et le tiers nord-oriental de la Basse-Navarre (Pays de Mixe et d'Ostabarret) à l'évêché de Dax. Les premières doctrines catholiques en souletin n'apparaîtront que bien plus tard, vers la fin du siècle, grâce à Belapeyre (ce dernier précise toutefois qu'il fut précédé par un jeune prêtre dont l'essai, hélas perdu, ne fut pas concluant).

20. Ce point à ma connaissance n'a pas été expliqué. Que voulait dire Axular? Que le basque était parlé ailleurs que dans les sept provinces? Cette interprétation, apparemment portée par la lettre du texte, me paraît difficilement admissible, car Axular devait suffisamment connaître la région, y compris dans sa partie péninsulaire, pour ne pas supposer une telle extension de la langue, et pour savoir qu'il avait déjà taillé bien large. Cette lecture aurait été envisageable comme une allusion à l'emploi du basque dans certaines zones situées aux portes des provinces, ainsi Bayonne à l'entrée du Labourd, où la proximité et le voisinage devaient assurer une certaine présence au basque, mais le fait que l'expression bertce anhitz leccutan 'dans beaucoup d'autres endroits' soit utilisée rend ceci également peu probable. Peut-être faut-il lire autrement ces lignes : Axular évoque la diversité des parlers et pour cela après avoir cité les différentes provinces, supposées chacune être porteuse d'une variété de langue, il fait ce rajoût pour indiquer que la diversité va en réalité bien au delà des limites provinciales; bref qu'elle se rencontre en bien d'autres endroits, à l'intérieur même des provinces citées.

21. En matière de morphologie lexicale, seule est mentionnée la forme de palatalisation apparaissant dans les dérivés hypocoristiques, et notamment dans le suffixe- $t t o /-x o$. Axular affirme que ceux qui parlent bien le basque ont une mauvaise opinion des dérivés privilégiant la chuintante $(x o)$.

22. La variation morphologique - ei vs -er est citée par Liçarrague dans son lexique destiné aux Souletins. Par ailleurs il l'utilise de façon systématique dans son ABC, et son instruction, dans le prologue desquels il indique avoir utilisé un basque conforme à celui des régions où la religion réformée était pratiquée.

23. Le cas de la paire irakurtzea vs leitzea 'lire'n'est peut-être pas un cas de variation dialectale : le doublet (sous des réalisations diverses des léxèmes) semble attesté dans la plupart des dialectes. Mais ceci ne signifie pas que les choses étaient ainsi perçues par Axular.

24. Les formes lexicales faisant référence à des parlers d'outre-Bidassoa sont barridea, esatea et zalduna. Barride est une forme des parlers de Navarre (bien qu'Azkue la mentionne également en Labourd frontalier à Ainhoa); esatea et zalduna également, mais ces derniers vocables sont aussi utilisés en Guipuscoa et en Biscaye.

25. Axular n'abandonne pas la graphie de Materre dans Guero, mais il la note en marge, ainsi qu'il l'indique dans son prologue. Par ailleurs, dans son approbation à l'ouvrage de Materre il l'avait lui aussi employée (meregi pour l'actuel merexi).

26. Materre prescrit dans la deuxième édition de sa Doctrine la maniẻre dont les marins devront utiliser son livre pour prier collectivement en mer, un marin lisant à haute voix, ceux sachant lire suivant silencieusement la lecture sur leur propre livre, car il estime qu'il n'y aura pas de marin sachant lire qui n'aura pas ce livre (Erran beça çuetaric batec appurbat gora eta haguitz orai hemen ibenico dudan othoitza : Eta bitartean eduqui beçate bertcec ere hartan gogoa, ençun beçate, edo norc bere liburuetan ixilic iracur beçate, ceren estimatcen dut ez-tela icanen bat-ere iracurtcen daquien marinelic liburu haur içanen eztuenic.) 
27. Cet avis figurant dans le corps du texte, nous n'avons pas introduit ces vers, au nombre de 26 , dans le recueil de l'appendice.

28. Seuls sont également en basque, les titres des deux parties de l'œuvre à l'intérieur du livre, et le titre du glossaire; peut-être aussi le sonnet en l'honneur de Sauguis et l'épitaphe en hommage à Arrain, deux poèmes apparaissant dans l'exemplaire de Bayonne, et placés en fin d'ouvrage, si on les considère comme des paratextes relevant des dédicaces et hommages de l'auteur.

29. On peut se demander si la traduction des proverbes ne répond pas également, au moins partiellement, à l'emploi du français comme langue de métalangue. C'est ce que semble indiquer le sous-titre de cette partie dans l'ouvrage d'Oihenart: Interpretation des proverbes basques. Ce qui se trouuera en cette interpretation, escrit en lettre Italique, sont des adjoustemens faits au texte Basque, pour une plus grande explication d'iceluy.

30. Je n'ai pas introduit dans le corpus l'avis venant en préambule au manuscrit de Medizione cerurat heltceco baitezpadacoac, anonyme que P. Charritton est sur le point de publier. Ce manuscrit porte sur la page de couverture la date de 1651, écrite par la main qui a également copié le manuscrit. Il est toutefois difficile de se fier à cette datation, la graphie indiquant plutôt un texte du début du XVIII' siècle. L'avis qui précède le texte suit dans l'ensemble le modèle des prologues modernes mais contient des éléments des prologues de la période précédente.

31. La fin de l'ouvrage contient une petit catéchisme qui n'est pas en vers. Il est précédé d'un court texte, sans titre, qui pourrait être considéré comme un paratexte; les dévots y sont exhortés à enseigner les prières à ceux qui ne savent pas lire. Toutefois du fait de son absence de titre et de sa place dans le corps de l'ouvrage nous ne l'avons pas inclus dans le recueil des prologues.

32. Pour des raisons de place, je ne restitue pas dans l'annexe la préface de Gasteluçar, que les lecteurs peuvent aisément consulter dans l'édition d'Akesolo (1983). Je fais figurer par contre l'avis au lecteur.

33. A côté de ces prologues, on trouve les approbations et des vers latins en hommage à l'auteur intéressant à plus d'un égard. Sur ce sujet, voir la préface d'Altuna à son édition du ler livre du Manuel (1981), et également Mitxelena (1981).

34. Les vers destinés aux marins lecteurs, qui sont dans le second livre, et que nous avons évoqués plus haut dans le texte, illustrent cette situation. Ils envisagent les différentes circonstances de la vie en mer et de la pêche en proposant des prières de circonstances, y compris les plus dramatiques (mer calme et pénurie de vivres, échouage, homme à la mer, embarquement de fortune pour atteindre la côte, etc...). Faut-il les penser comme des textes devant être appris par cœur et récités ou chantés dans ces circonstances ainsi que le dit l'auteur? Ne sommes-nous pas en présence plutôt d'un positionnement littéraire dans le cadre d'un ouvrage dépassant en fait sa nature fonctionnelle première ?

35. Le Manual devotionezcoa de 1627/1669 a deux dédicaces, venant en préambule de chacun des deux livres composant l'ouvrage. Celle du premier livre est adressée à Claudius de Rueil, Evêque de Bayonne, et celle du second livre à Miguel de Oiharart, Vicaire Général. 


\section{Bibliographie}

Argaiñaratz d'-, P. (1665) : Devoten breviarioa, Bosc, Bayonne; nouvelle édition conforme à la première par J. Vinson : 1910, Bertrand, Chalon-sur-Saône.

Agirre, P. (1996) : Athanase Belapeire : Catechima laburra (1696). Autoreraen garaia, nortasuna eta idazlanak, grafiak eta fonologia. Edizio kritikoa eta hiztegia, Thèse de doctorat, Université du Pays Basque, Vitoria.

Axular, P. de - (1643) : Guero, bi partetan partitua eta berecia, G. Milanges, Bordeaux; édition en facsimilé : 1988, Académie de la langue basque-Euskaltzaindia, Bilbao.

Cayuela, A. (1996) : Le paratexte au siècle d'or, Droz, Genève.

Cervantes, M. de - (1605) : El ingenioso hidalgo Don Quijote de la Mancha, Tome 1, édition révisée et mise à jour de Martín de Riquer, 1980, Planeta, Barcelone.

Compagnon, A. (1979) : La seconde main ou le travail de citation, Seuil, Paris.

Dechepare, B. (1545) : Lingva vasconvm primitia, F. Morpain, Bordeaux; édition en facsimilé, avec traduction allemande, anglaise, espagnole, française et italienne : 1995, Académie de la Langue basque - Euskaltzaindia, Bilbao.

Diccionario General Vasco - Orotariko Euskal Hiztegia (1987-), Académie de la Langue basque Euskaltzaindia, Desclée De Brouwer \& Mensajero, Bilbao.

Etcheberri (de Ciboure), J. (1627) : Manval devotionezcoa edo ezperen, oren oro escvetan erabilltçeco liburutchoa, G. Millanges, Bordeaux; édition facsimilée de la seconde édition de 1669 chez I. Mongirion Millanges à Bordeaux : 1978, Hordago, Saint Sébastien; édition critique du 1er livre par P. Altuna, 1981, Académie de la Langue basque - Euskaltzaindia, Bilbao.

Gasteluçar, B. (1686) : Eguia catholicac salvamendv eternalaren eguiteco necessario direnac, Desparatz, Pau; édition critique de L. Akesolo: 1983, Académie de la Langue basque - Euskaltzaindia, Bilbao.

Genette, G. (1987) : Seuils, Seuil, Paris.

Haramboure, J. (1635). Debocino escvarra, mirailla eta oracinotegvia, P. de la Court, Bordeaux.

Jimeno Jurio, J. M. (1997) : Navarra. Historia del Euskera, Txalaparta, Tafalla (Navarre).

Liçarrague, J. (1571a). Iesus Christ gvre Iaunaren Testamentv Berria, traduction basque du Nouveau Testament, traduction du Nouveau Testament; cf. T. Linschmann \& H. Schuchardt (1900).

Liçarrague, J. (1571b). Kalendrera, Bazco noiz daten, ilhargvi berriaren eta letra dominicalaren eçagutzeco manerarequin, \& ABC edo Christinoen instrvctionea othoitz eguiteco formarequin P. Hautin, La Rochelle, deux ouvrages en un volume, voir T. Linschmann \& H. Schuchardt (édit.) (1900).

Linschmann, T. \& Schuchardt, H. (édit.) (1900). I Leiçarragas Baskiche Bücher von 1571 (Neues Testament, Kalender und $A b c$ ), Trübner, Strasbourg; édition facsimilée : 1990, Académie de la Langue basque - Euskaltzaindia, Bilbao.

Materre, E. (1623 [1617]) : Dotrina christiana. Bigarren impresionearen debocinozco othoitz eta oracino batçuez berreturic, $2^{\circ}$ édition ( $1^{\prime *}$ édition de 1617 perdue), J. Millanges, Bordeaux.

Mitxelena, K. (1963) : 'Eranskin gisa', Egan, 1-3, 78-79.

Mitxelena, K. (1981) : 'Patxi Altunari erantzunez', Euskera, 2, 617-626.

Montoya Martínez, J. \& Riquer, I. de -. (1998) : El prólogo literario en la Edad Medieval, UNED, Madrid.

Mujika Casares, J. A. (1997) : Euskal ortografiaren hastapenak Iparraldeko literaturan, Thèse de doctorat, Université du Pays Basque, Vitoria.

Oihenart, A. d'-. (1657) : Les proverbes basques recueillis par le Sr d'Oihenart, plus les poésies du mesme auteur; édition critique trilingue par J.-B. Orpustan avec traduction française et espagnole, et contenant les poèmes édités postérieurement (1664?) : Proverbes et poésies basques (1657-1664), 1992, Izpegi, Baigorri. 
Oyharçabal, B. (1999) : Euskarazko irakaskintzaren historia ororen eskolen ildotik, iraultzaren frantses garaiko eskola liburuxka bat, Lapurdum, Bayonne.

Oyharçabal, B. (en cours.) : Lapurterazko literatura 17. eta 18. mendean : zenbait gogoeta, CNRS, Bayonne.

Porqueras Mayo, A. (1957) : El prólogo como género literario. Su estudio en el Siglo de Oro español, Consejo Superior de Investigationes scientificas, Madrid.

Rigolot, F. (1986) : 'L'imaginaire du discours préfaciel', Studi di litteratura francese, Firenze.

Salaberri Munoa, P. (1998) : 'Gero liburuaren koherentziaz eta egituraketaz', Lapurdum, 3, 241-271, Bayonne.

Spang, K. (1987) : 'Hacia una terminología textológica coherente', in J. Cañedo \& I. Arrellano (édit.), Edición y anotación del texto del siglo de Oro, 319-338, EUNSA, Pampelune.

Tartas, J. (1666) : Onsa hilceco bidia, J. Rouyer, Orthez; édition facsimilée et édition critique préparée par A. Altuna, 1995, Université de Deusto, Bilbao.

Tartas, J. (1672) : Arima penitentaren occupatione devotac, J. Rouyer, Orthez; édition critique de P. Altuna, 1996, Mensajero, Bilbao.

Tripet, A (1992) : Montaigne et l'art du prologue au XVIe siècle, Champion., Paris.

Villasante, L. (1979) : Historia de la literatura vasca, seconde édition révisée et complétée, Editorial Aranzazu, Burgos.

Vinson, J. (1891) : Bibliographie de la langue basque, Maisonneuve, Paris; seconde édition annotée par Julio de Urquijo, 1984, Seminario de Filología Vasca "Julio de Urquijo", Saint Sébastien. 


\author{
Recueil des prologues auctoriaux \\ des ouvrages en basque \\ des XVI ${ }^{e}$ et XVII ${ }^{e}$ siècles : \\ textes et traduction ${ }^{1}$
}

\title{
LIÇARRAGUE
}

Adresse aux Basques de Liçarrague en préambule à la traduction du NouveauTestament :

\section{HEVSCALDVNEY}

Heuscarazco hitzac, nola scribatzen, hala letra guciequin Latinén ançora pronuntiatzen-ere dirade : eta $u$ vocala, bethequi, ou baliz beçala. Berçalde Testamentu berriaren heuscarazco translatione hunetan hitz bakoitz batzu letra cheheagoz textu artean eçarri içan dirade, eçagun dençat ecen hec teztuan aditzen diraden hitzac içanagatic, eztiradela ordea textu gorputz berecoac, baina declaragarri iarriac. Gaineracoaz den becembatean, batbederac daqui heuscal herrian quasi etche batetic bercera-ere minçatceco manerán cer differentiá eta diuersitatea den : raçoin hunegatic sensu eguiazcotic aldaratu gabe, lengoageaz den becembatean ahalic guehiena, guciey adi eraciteari iarreiqui içan gaitzaitza, eta ez choil edocein leku iaquineco lengoage bereciri : eta badaquigu ecen demborarequin anhitz hitz eta minçatzeco manera, eridenen dela obra hunetan bercera hobequi erran çatenic : halacoetan, gauçá ceren den daquitenetaric batbedera, orhoituren da, othoi, ecen hunelaco gauçác, guciz lengoage oraino vsatu gabe batetan, ecin behingoaz halaco perfectionetan iar daitezquela, nola behar bailiçateque : guciagatic-ere minçatzeco manerán anhitz arrastatu gabe, Iaincoaren hitz purari iarreiquiteco desira dutenéc, sporçu dugu eridenen dutela (suporturequin) cerçaz contenta. Eta baldin sperança dugun beçala, oraindrano eguin den hunetán heuscaldunac goçoric edo edificationeric hartzen badu, hunetan emplegatu içan diradenéc bihotz harturen duté, oraindanic gogo-ere duten beçala, eguin denaren berriz ikusteco eta corrigitzeco : bayeta, baldin Iaunac hala placer badu, passage difficilenén declaragarri annotationén eçarteco. Iaincoac othoi, haren desohoretaco den doctrina gucia eçagut eraciric eta confundituric, haren ohoretaco dena bethi entreteni eta auança decala Iesus Christ bére Seme gure Iaunaren icenean. Amen.

\section{Aux Basques}

Les mots basques, semblablement à ceux du latin, se prononcent ainsi qu'ils s'écrivent dans toutes leurs lettres : et la voyelle $\boldsymbol{u}$, pleinement, comme s'il s'agissait de ou. Par ailleurs, dans cette traduction du Nouveau Testament, quelques rares mots ont été écrits dans des lettres plus menues au sein du texte, afin que l'on voie que ceux-ci, bien qu'ils soient des mots qui y sont entendus, n'appartiennent pas au même corps de texte, mais qu'ils ont été introduits à fin d'éclaircissement. Pour le reste, chacun sait quelle diversité et variation il existe en Pays Basque, presque d'une maison à l'autre, dans la manière de parler : pour cette raison en ce qui concerne la langue nous nous sommes attachés, sans nous éloigner du sens véritable, à faire comprendre le plus possible à tous, et pas seu- 
lement à suivre le parler particulier d'un lieu donné, quel qu'il soit : et nous savons qu'avec le temps on trouvera beaucoup de mots et de manières de dire dans cette œuvre que l'on aurait pu mieux exprimer autrement : dans de tels cas, chacun se souviendra, de grâce, puisqu'il s'agit d'une chose que l'on sait, que ces choses la première fois ne peuvent atteindre la perfection ainsi qu'il le faudrait, en particulier dans une langue encore non usitée : malgré tout, nous sommes confiants que sans s'arrêter beaucoup à la manière de parler, ceux qui ont le désir de suivre la pure parole de Dieu trouveront (en exerçant leur patience) leur contentement. Et si, comme nous l'espérons, le Basque trouve du plaisir et quelque édification dans cette traduction faite à ce jour, ceux qui l'ont réalisée prendront courage, comme ils en ont déjà l'intention, pour corriger et revoir ce qui a été fait : et aussi, si cela plait à Dieu, pour établir des annotations éclairant les passages les plus difficiles. Que Dieu, ayant fait connaître et confondu toute doctrine qui est à son déshonneur, conserve et fasse avancer celle qui est en son honneur, au nom de Jésus Christ son fils notre Seigneur.

Avertissement précédant l'ABC de Liçarrague (1571) :

HEVSCAL-HERRIAN GAZTETASSVNAREN iracasteco carguä dutenér eta goitico guciér, I. Leiçarraga Berascoizcoac Iaincoaren gratia desiratzen.

Berce natione guciéc, ceinec bere lengoagean beçala, Heuscaldunac-ere berean duençat, certan iracurtzen ikas ahal deçan, eta nola Iaincoa eçagutu eta cerbitzatu behar duen, necessario estimatu vkan dut, A B C haur berce instructionerequin Heuscaraz-ere iar ledin : eta hunetacotzat, Iaincoac eguin drautan gratiaren araura, haren laudoriotan emplegatu içan naiz : dacussadalaric bada, ecen Iainco eguiazcoaren eta Iesus Christ haren Seme guregatic mundura ethorri içan denaren eçagutzera lacho eta ansicabe direnéc contu gutia hunez eguinen dutela : baina berac manu beçala Iaincoa eçagutu eta cerbitzatu desir dutenéc, segur naiz, bere probetchuric eguinen dutela : eta halacoacgatic ber, haur eguin içan da. Eta minçatzeco maneraz den becembatean, Heuscal-herrian religionearen exercitioa den lekuco gendetara consideratione guehiago vkan dut, ecen ez bercetacoetara : eta haur, sperançaz ecen Instructione hunec lehenic, eta orain behin guehienic, hetan cerbitzaturen duela. Baina bithartean, iracasteco cargua duçuenac, hirur punctuz principalqui aduertitu nahi vkan çaituztét. Lehena da, aitzinago hel daitezqueno, cer den vocala edo consonanta, diphtongoa edo syllabá, haourrér ikasten demboraric emplega eraci gabe, liburutcho hunetaco formari simplequi çarreitzaten. Bigarrena, vngui eta trebequi lehen-vicitic letreyatzen haourrér iracats dieceçuen. Hirurgarrena, iracurtzera datocenean, Colonaren, Commaren, edo Punctuaren differentiá ceric den, anhitz fundatu gabe, hitzac distinctoqui eta claroqui pronuntia eraciz, paussuén eguiten costuma ditzaçue. Iaincoac, othoi, çuen trabaillua prospera eta benedica deçala, Amen. Rochellan Vrriaren lehenean, 1571.

J. de Liçarrague souhaite la grâce de Dieu à ceux qui ont en charge l'instruction de la jeunesse en Pays Basque et à tous leurs supérieurs.

Afin que la nation basque dispose, comme toutes les autres nations chacune dans sa langue respective, de quoi pouvoir apprendre à lire, et comment il lui faut connaître et servir Dieu, j'ai estimé nécessaire que fût mis en basque cet $\mathrm{ABC}$ 
avec les autres instructions : et pour cela je me suis employé à faire les louanges de Dieu, conformément à la grâce qu'il m'a donnée. Tandis que je vois que ceux qui sont insouciants et indifférents à la connaissance du Dieu véritable et de Jésus Christ son fils descendu en ce monde pour nous, feront peu de cas de ceci, je suis sûr que ceux qui ont le désir de connaître Dieu et de le servir comme celui-ci l'a commandé, en tireront profit; et c'est pour eux seulement qu'il a été fait. Et en ce qui concerne la manière de parler, j'ai eu plus de considération pour les gens du lieu où la religion est exercée, que pour ceux d'autres endroits du Pays Basque : et ceci, dans l'attente que c'est parmi eux que d'abord cette instruction servira le plus en premier lieu. Mais cependant j'ai voulu vous avertir, vous qui avez charge d'instruire, de trois points principalement. D'abord, suivez simplement la forme de ce livret, sans faire employer de temps aux enfants à apprendre ce qu'est une consonne, une voyelle, une diphtongue ou une syllabe, jusqu'à ce qu'ils soient plus avancés. Deuxièmement, dès le départ apprenez aux enfants lettres et syllabes bien et de bonne manière. Troisièmement, lorsqu'ils viennent lire, habituez-les à faire les pauses, en leur faisant prononcer les mots clairement et distinctement, sans chercher beaucoup à établir en quoi consiste la différence entre le point virgule, la virgule ou le point. Que Dieu, de grâce, fasse prospérer et bénisse votre travail, Amen. A La Rochelle, le 1er octobre, 1571.

\section{MATERRE}

Adresse aux Basques de Materre en tête de la première édition de Dotrina christiana (1617) :

\section{EVSCALDVNEI}

Miretsico duçue agian nic (Euscal-herrico ez naicelaric) Euscaraz esquiribatceco ausartciaren hartcea. Baiña baldin considera ba-dadi edirenen duçue eztela gauça hunetan ausartciaric, eta ez cer miretsiric : aitcitic bertcela eguin ba-nu miretsi behar çatequeyela eta erran ahanci citçaitala neure eguinbidea. Ceren Iaincoac niri hitzcunça hunen ikasteco ance [texte : ence] appur bat eman derautanaz gueroz, iduritcen çait hoben nuqueyela, eta ere ezagutça gutitaco eta esquer gabe içanen nincela, baldin Euscal-herrian ikassia Euscal-herrico [texte : herico] probetchutan emplegatu ez-panu.

Euangelioco cerbitçari alfer hura gaztigatu çuen bere nabusiac, ceren irabacian erabiltceco [texte : erabiltceo] errecibitu çuen talentua [texte : talntua] eta dirua estalia eta ehortcia eduqui çuen. Handic içan naiz [texte : noiz] ni ere beldur hala gertha cequidan, baldin Euscaraz minçatceco [texte : mençatcero] ardietsi [texte : ardiesi] dudan talentua eta iaquina arima irabacian emplegatu gabe ehortcia eta gordea eduquitcen ba-nuen. Eta etçait iduri asco dela Cadiratic predicatuz probetchu eguitea baiña are vste dut esquiribuz ere behar dela enseyatu eta trabaillatu.

Eta nola lanac cimendutic behar baitu hassi, eta gure salbamenduco obraren cimendua baita Doctrina Christiana, halatan nic ere, handic hasten naicela, hartu dut gogo liburutto hunen eguiteco, eta iendartera atheratceco, hunetan (bertce eracusleric eztenean) ikus dadin laburzqui cer-ere sinhetsi, obratu, eta escatu behar baita; Eta guero ikus dadin halaber nola behar den Euscara esquiribatu eta iracurtu. 
Gaiñeracoan badaquit Euscal-herrian añhitz moldez minçatcen direla, eta nor bere herrico Euscara çaicala hoberenic eta ederrenic. Eta handic gogoac [texte : gogoca] emaiten [texte : emaitan] deraut ene esquiribatceco molde haur etçayela guztiei ongui idurituco : Baiña nahi dut iaquin deçaten halacoec nic [texte : nec] hitzcuntça hunetan daquidana Saran ikassia dudala, eta hango Euscara ongui erabiltcen ba-dut ez naicela gaitz erraiteco, eta ez arbuyatceco, ceren ez paitaquit nic hangoa baicen. Ordea ea Saraco Euscara denz Euscal-herrico hoberena eta garbiena, ez naiz ni hartan sartcen, bat-bederac emanen du bere iduriric. Eta Saraco Euscara hunetcaz content eztenac ezquiriba beça bertce Euscara hobeago batez eta hobequiago, ez-naiz ni hargatic bekaiztuco, eta ez imbidios içanen.

Finean hemen den guztia borondate on batequin Iaincoaren ohoretan eta arimen probetchutan eguina da: Hala beraz errecibi eçaçue, eta çuen oracinoetan eguin naçaçue partale.

\section{Aux Basques,}

Vous vous étonnerez peut-être que, n'étant pas du Pays Basque, j'aie l'audace d'écrire en basque. Mais si on la considère, vous verrez qu'il n'y a en cette chose nulle audace, et rien pour s'étonner : au contraire c'est si j'avais fait autrement qu'il aurait fallu s'étonner et me dire que j'avais oublié mon devoir. Car puisque Dieu m'a donné suffisamment de dispositions pour apprendre cette langue, il me semble que j'aurais commis une faute, et que j'aurais été peu reconnaissant et ingrat, si je n'avais pas employé au bénéfice du Pays Basque ce que j’y avais appris.

Dans l'évangile, le serviteur paresseux fut puni par son maître, car il avait gardé caché et enterré le talent et l'argent qu'il avait reçus afin de le faire fructifier. J'ai craint qu'il ne m'arrivât la même chose, si je tenais caché et enterré, sans l'employer au bénéfice des âmes, le talent et le savoir dont j'ai été doté pour parler basque. Et il ne semble pas qu'il suffise d'en tirer profit en prêchant de la chaire, mais je crois qu'il faut s'y employer et y travailler par écrit également.

Et comme le travail doit commencer par les fondements, et le fondement de notre œuvre salvatrice étant la doctrine chrétienne, j'ai moi aussi, commençant par là, formé le projet de faire ce petit livre, et de le mettre à la disposition du public, afin qu'on y trouve (quand il n'y a pas d'autre enseignant) ce qu'il faut croire, œuvrer et demander; et qu'ensuite l'on voie de même comment il faut écrire et lire le basque.

Pour le reste je sais qu'on parle en Pays Basque de bien des manières, et que chacun trouve son basque plus beau et meilleur. Et en conséquence de ceci, il me vient à l'esprit que ma manière de m'exprimer ne paraîtra pas bonne à tous. Mais je veux que ceux-là sachent que ce que je sais en cette langue je l'ai appris à Sare, et si j'emploie bien le basque qu'on y parle, je ne dois pas être dénigré, et méprisé, car je ne connais pas d'autre basque que celui-là.

Quant à savoir si le basque de Sare est le plus pur et le meilleur du Pays Basque, c'est un sujet que je n'aborderai pas; chacun donnera son opinion. Et que celui qui n'est pas satisfait de ce basque écrive mieux et dans une langue meilleure, cela ne me rendra ni jaloux ni envieux. 
Enfin, tout ce qui est écrit ici l'a été avec bonne volonté, en l'honneur de Dieu et pour le bénéfice des âmes. Recevez-le ainsi, et accordez-moi une place dans vos prières.

Avertissement au lecteur de Materre en tête de la deuxième édition de Dotrina christiana (1623) :

\section{IRACVRCAILLEARI}

Nola bethiere aprendiz eta ikas-behar baicara, eta gaitz baita obra baten alde guztiz jugen nehorc ecin arbuya deçaqueyen beçala eguitea, beha egotu naiz ea cer erraiten çuten iendec nic cenbait urthe [texte : vrthute] duela esquiribatu nuen Guiristinoaren Dotrinaz, eta ediren dut ecen batçuen artean hartçaz cebilan solhasa, eta erraiten cena cela Dotrina eta Dotrinaren declaratinoa ez elkarrequin, baiña beregainqui eta bereciqui bi partetan ibeni behar cirela. Bada halaco hei [?, texte : hrl] atseguin eguiteagatic, eta neroni [texte : renoni] ere eztela gaizquiago idurituric [texte : iduriturit] bereci ditut elkar ganic, eta eguin bi parte. Eta ceren añhitz baita Euskal-herrian iracurtcen daquienic, baiña ez Euskara baicen bertce hitzcunçaric aditcen, halatan eguin ditut halacoenzat Euscaraz debocinozko othoitz eta Oracino batçuc, goicetan, arratsetan, eta bertce añhitz denboratan eta ocasinotan eguin eta erran ahal ditezqueyenac [texte : ditezqucyenac], ceinetçaz eguiten baitut hirurgarren partea, Guztiac dohaci borondate on batez eguinac [texte : egninac] : eguieçu beguitarte, eta errecebi itçaçu nic ceureac [texte : ceurerc] ba-lira errecibi niţ̧an nahi cenduqueyen beçala.

\section{$\mathrm{Au}$ lecteur,}

Comme nous sommes toujours apprentis et en nécessité de nous instruire, et comme il est difficile de faire une œuvre juste en tous ses aspects telle que nul ne pourrait la rejeter, j'ai attendu, pour savoir ce que disaient les gens de la Doctrine chrétienne que j'avais écrite il y a quelques années, et j'ai constaté que le propos circulant à son sujet entre certaines personnes, et ce qui se disait, était qu'il fallait que la doctrine et l'explication de la doctrine ne fussent pas ensemble, mais qu'elles fussent mises en deux parties, séparées et indépendantes. Ainsi, pour faire plaisir à ces gens, et m'ayant paru à moi aussi qu'il n'en est pas plus mal ainsi, je les ai séparées et j'en ai fait deux parties. Et comme il y a beaucoup de gens au Pays Basque qui savent lire, mais qui n'entendent d'autre langue que le basque, j'ai écrit pour eux en basque des oraisons et des prières de dévotion que l'on peut dire le matin, le soir, et en beaucoup de moments et d'occasions, et avec lesquels j'ai composé une troisième partie. Tous ces textes ont été faits avec bonne volonté : faites-leur bon accueil, et recevez-les ainsi que vous souhaiteriez que je les reçusse s'ils étaient de vous.

\section{ETCHEBERRI DE CIBOURE}

Trois avertissements au lecteur d'Etcheberri de Ciboure en tête du Manual devotionezcoa (1627/1669),, en préambule à l'ensemble de l'ouvrage : 


\section{MANVALAREN IKHASTERA IRATÇARMENDVA.}

Bat bedera mela bedi duen offiçioaz,

Eta Guiristiño dena, prestu içatecoaz.

Bercela du, Christauaren gueçurtatçen deitcea.

Eta Eliçari bere goratçen ohorea.

Beguira daudenac ditu edificatçen gaizqui,

Eta gende infidelac ere sortçen gogorqui.

Dolu belçez estalçen du corte dohatsuena,

Eta arima damnatçen, nihoiz hillen eztena.

Hauc gustiac, Christau falsoac ohi ditu obratçen

Noiz ere baita, bekhatu mortalean erortçen

Hartaracotz nekha çaite, ikhasten Manuala

Eta faltetaric guarda, hura obraţ̧en duçula.

\section{EXHORTATION À L'APPRENTISSAGE DU MANUEL}

Que chacun se mêle de son office

Et le chrétien d'être sage.

Car, sinon, il dément son appellation de chrétien,

Et il prive l'église de son honneur.

Il édifie mal ceux qui l'observent,

Et rend tout à fait insensibles les infidèles.

Il couvre d'un deuil noir la cour des bienheureux,

Et damne l'âme, qui ne mourra jamais.

Toutes ces choses sont réalisées usuellement par le faux chrétien

Lorsqu'il tombe dans le péché mortel.

Pour cette raison prenez la peine d'apprendre le Manuel

Et, tandis que vous le mettez en œuvre, préservez-vous des fautes.

IRACVRTCAILLE DEVOTARI EGVILLEAC

LIBVRV HVNEN MANERAZ ABISVA.

Gviristiñoa, eman diat escarazco versutan,

Catholico manuala neure asti ordutan

Ikhussiric nola bainaiz iaiatcez [texte : iatatcen] escalduna

Gure natioa dela copla maite duena.

Hartaracotz iaquiara diat versus eçarri,

Lasterrago ikhas eta maizago aipha garri.

Lehenago nonbait vrrun Greçiaco partetan

Herrico legueac eman ohi ituen cantetan

Nola cantac maiz baitire munducoen ahoan,

Hala cantez orhoituric, maiz çitusten gogoan,

Hequin bada costuma onaz orhoituric lerroca

Manuala eman diat, den beçala coplaca.

Bañan nihorc eztemala beharria hitçera,

Hambat nola hitz azpian ehorçia denera.

Guehiago ahal beçain humilqui aut othoizten,

Obratcho hau mespreçia gogorqui ezteçaquen.

Hafteac gaitçac direla errana duc communqui

Hunen gañean eguinen dic cembait berçec hobequi. 
Avis de l'auteur au dévot sur la manière de ce livre

Chrétien, j'ai écrit en vers basques,

Le manuel catholique durant mon temps de loisir, Ayant observé, étant basque de naissance,

Que notre nation aime les couplets.

Pour cette raison délibérément je l'ai mis en vers

Afin qu'il soit plus vite appris, et plus souvent mentionné.

Jadis quelque part au loin dans les contrées de Grèce

Les lois du pays étaient mises en couplets :

Comme les chants viennent souvent aux lèvres des gens,

Ainsi, en se souvenant de ceux-ci, ils avaient les lois fréquemment à l'esprit.

Me rappelant donc de leur bonne coutume, ligne à ligne,

J'ai mis en couplets le Manuel tel qu'il est.

Mais que nul ne prête l'oreille aux mots

Autant qu'il le fait à ce qui est enfoui sous eux.

Encore plus : je te supplie très humblement (lecteur)

De ne point mépriser durement cette petite œuvre.

Il est dit communément que les débuts sont difficiles,

A partir de cet essai, quelqu'un d'autre fera mieux.

\section{LIBVRVAREN ERREPARTIMENDVAZ.}

Libvrv hau guztia duc bi partetan berezten Iaquin behar gauçac ditic lehenac iracasten Bi Garrenac deuotionen eguiteco othoitçac, Ceiñac behar bailituzque erran Christau bakhotçhac.

Halaber duc lehenbiçi liburua bietan,

Nola baituc Ikhussiren erdiratçen partetan.

Lehen biçicoac gauça aiphatçentic communac,

Erkhaiñetan bat bederac iaquin behar tuenac.

Bertceac guero, Guiçonen fin çazpi azquenecoac,

Guiristinoac gau eta egun finean ${ }^{2}$ itçultçecoac :

Hurren parteac halaber bi gauçatic condatçen,

Bakkun eta oratione bikkunac iracasten.

Azquenean laburqui duc eçarri manuala

Edo ceiñec pena gutiz har diroen becala.

Adisquidea, ikhasetçac othoi deuotionez,

Nola nic baitarozquiat escaintçen gogo onez.

Nequearen golardotzat deus eztiat galdetçen,

Lekhat, gogotic emplega adin hauquin ikhasten.

De la composition du livre

Ce volume tout entier se compose de deux livres

Le premier enseigne les choses qu'il faut savoir

Le second les prières pour faire les dévotions

Que chaque chrétien devrait dire.

De même, le premier livre, en deux parties, 
Ainsi que tu le verras, se divise.

La première parle des choses communes

Que chacun doit savoir sur le bout des doigts,

L'autre, ensuite, des sept fins dernières de l'homme

Que le chrétien jour et nuit doit à la fin ${ }^{3}$ considérer.

Le livre suivant de même conte deux choses,

Et enseigne les oraisons simples et doubles ${ }^{4}$.

Finalement le manuel est résumé

De manière à ce que quiconque puisse le recevoir avec peu de peine.

Ami, je t'en prie, apprends ces oraisons avec dévotion,

De même que je te les offre avec bonne volonté.

Je ne demande rien en récompense de ma peine,

Sinon que tu t'efforces de bon cœur de les apprendre.

Avertissement au lecteur d'Etcheberri de Ciboure en tête du premier livre du Manuel de dévotion de 1627.

\section{IRACVRTCAILLEARI ABISVA.}

Catonec ohoratudic versuaz Italia,

Pibraquec Françia eta Beriñec Españia.

Berriroqui minzatuduc, çuhur Ader Gascoiña.

Guztietaric hautaçac Iesus Christen guidoiña

Ea beraz ikhas eçac saluatçeco artea,

Ceina baita gaiñeraco çuhurtçien Andrea.

Hirur gauça çiadutçac, errandudan arteac,

Non ençerratcen baitire Iesus Christen legueak.

Hauc direla Guiristinoa beharduc seguratu

Sinhets, obra, behardela, Iongoicoa [texte : Iongoica] othoiztu,

Sinhestea asqui eztuc, non eztuen obratcen,

Ecen Iaunac obraradic guehienic behatzen,

Othoitcean lauda eçac lehen etabiciric,

Eta guero esca aquio behar duen gauçaric.

Içan duen fauoreaz, guero bihur esquerra,

Aldarearen oinera goiz eguinic lasterra,

Eguinbide hauc guztiac nahi baituc ikhassi,

Ikhusetçac [texte : ikusetçat] nola diren elkharrequin nahassi.

Othoitzteco façoinaren ordean exemplua,

Christauaren doctriñatic ikhuz eçac hartua :

Ceren Christoren hitçac maiz behar tugun ahoan,

Eta oracioneac guero hequin ondoan.

Ecen ardiastecotçat beharrezco premia,

Sinhetçac, othoitza dela gustiz moian handia,

Guero sarri tuc othoitçac, berehala esquerrac,

Iaunaren ganic fiñean, partiada ederrac.

Catholicoen doctriña hala diat moldatu,

Othoitz eguiten duela, gogoan deçan hartu.

Guero cer esqua aiteque, gauça hobeagoric,

Manamentuen gratia baiño complitcecoric? 
Illhabethe oro behin iracurrac guztia, Iesus Christoc munduari declaratu eguia.

Noicic behingoac ere, heure eguin bidera, Atçarturenau manuen ereduz bizitcera.

Baiñan othoitz eguiteco, apartean lekhua, Iduquiçac çartço eta soiñutic vrrundua.

Paretean hedaturic, Imagina ederqui,

Eta vr benedicatua bazterrean chahuqui.

Gogoetac khassaturic, lurreraiño belhauna,

Guero plega eta eçagut, nola aicen illhauna.

Nahiz vda dela eder, edo aspre negua,

Iaincoaren othoizteco hauduc erremangua.

Avis au lecteur

Caton a honoré en vers l'Italie,

Pibrac la France et Verino ${ }^{5}$ l'Espagne;

Récemment Ader le sage Gascon a parlé.

Parmi tous choisis 1'enseigne de Jésus Christ

Et apprends donc l'art du salut,

Qui est la maîtresse des autres sagesses.

L'art que j'ai mentionné comprend trois choses,

Dans lesquelles sont contenues les lois de Jésus Christ.

Chrétien, tu dois être sûr que ce sont celles-ci :

Qu'il faut croire, œuvrer, et prier Dieu.

Croire n'est pas suffisant, si tu n'œuvres pas,

Car le Seigneur regarde le plus à l'œuvre.

Dans la prière loue-le d'abord

Puis demande-lui les choses qu'il te faut.

De la faveur que tu as reçue, ensuite remercie-le,

En accourant tôt au pied de l'autel.

Si tu veux apprendre tous ces devoirs,

Considère comment ils sont entremêlés.

Quant au modèle sur la façon de prier,

Vois-le, pris de la doctrine chrétienne :

Car les paroles de Jésus Christ doivent être souvent sur nos lèvres,

Et les oraisons après elles.

Pour obtenir la satisfaction du besoin pressant,

Crois, que la prière est un moyen très puissant.

Puis, tu trouveras bientôt les prières, et aussitôt les remerciements,

A la fin, de beaux départs accordés par le Seigneur ${ }^{6}$.

J'ai ainsi composé la doctrine des catholiques

Afin que tu l'aies à l'esprit lorque tu pries.

Ensuite, quoi peux-tu demander de mieux

Que la grâce d'accomplir les commandements?

Lis en entier une fois par mois

La vérité déclarée au monde par Jésus Christ.

Une lecture occasionelle également te poussera à ton devoir,

A vivre selon les commandements.

Mais tiens le lieu de tes prières à part, 
Eloigné du tapage et de la musique,

L'image sainte joliment déployée sur le mur,

Et l'eau bénite placée proprement sur le côté.

Ayant chassé les pensées, le genou plié jusqu'au sol,

Incline-toi ensuite, et vois comme tu es insignifiant.

Que l'été soit beau, que l'hiver soit rude,

C'est là la manière pour prier Dieu.

Avertissement d'Etcheberri de Ciboure en tête du second livre du Manuel de dévotion de 1627.

\section{IRACVURTÇAILLEARI ABISVA}

Huneraño mintçaturic gauça iaquitecoez,

Orain mugaz daguigun hitz othoitz eguitecoez.

Ecen hequin moianez Iaun Cerucoac guztiac,

Escu puchantaz estaltcen tic guiçonen premiac.

Eta beraz ikhaz eçac Iañcoaren othoizten,

Eta oren guztietan behar denaz ertchatcen [texte : ertehatcen].

Hartaracotz hemen diat antcea declaratu,

Eta haren eredura exempluac moldatu.

Asqui dena ene penec liquetec irabaci,

Baldin asti orduetan nahi baituc ikhassi.

Bañan errac astiroqui othoitcetan lehenic,

Othoiztea cein baitago hurren plaman etciñic.

Ecen othoitcen han diat moldea arrimatu,

Eta Iañcoari mintço natçaiola, moldatu.

Hunec ernaturen daroc bihotça othoiztera,

Pensatcean, nolaco den, othoizteco manera.

Othoiztecotçat hau duquec preparationea,

Handic beraz has eçaquec heure orationea.

Avis au lecteur,

Ayant parlé jusqu'ici des choses à savoir,

Maintenant en heure parlons des prières à dire.

Car par leur moyen le Seigneur du ciel

Couvre d'une main puissante tous les besoins des hommes.

Et, donc, apprends à prier Dieu,

Et à toute heure à l'implorer de ce qui est nécessaire.

Pour cela j'ai ici exposé une méthode,

Et suivant ce modèle établi des exemples.

Mes peines auront été assez récompensées,

Si durant tes loisirs tu veux les apprendre.

Mais dis d'abord lentement parmi les prières

Celle qui est couchée dans la page suivante.

Car là j'ai placé la manière de prier,

Que j'ai composée comme une adresse personnelle à Dieu.

Ceci incitera ton cœur à prier, 
En pensant, comment est la façon de prier.

Ceci sera la préparation à la prière,

Tu pourras donc par là commencer ton oraison.

\section{HARAMBOURE}

Avertissement au lecteur de Haramboure dans Debocino eskuarra $(1635)^{7}$ :

IRACVRCAILLEARI obraren iabeac.

Guiçonac ahal duqueien ontasun handienetaric bata (Adisquide debota) da Oracinoa, cein baita, bere adimendua Iaincoagana alchatcea, hargatic nic ere dotrina hau çure beguien aitcinera athera dut nihoren erranetara eta erran ahal ditçaquetenetara batre behatu gabe. Eguiazqui ençun dut eta badaquit baţ̧uec minçatce mueta hau arbuiatcen dutela, berriz bercec bere herrietaco hizcunçaz [texte : hitcunçaz] nahi luquetela : baina bercela eguinic laudorioac baino neure herrico minçaiaz eguinic baiac gogoticago pairatuco ditut, halakotz ezteçala nihorc mirex baldin nahastecatuqui minço ezpanaiz, baina bat bederac debotqui erabil beça bere probetchutan, eta horra ene intencionea

Finean $H$ bestetan edireiten duçun lekhuan heren ordenako besta date : $F$ den lekhuan san Francesen Ordenacoa, berce besta escasac norc bere herrietan eliçatic ikhasten ditu, Iaincoac ungui goçatceco garacia diçula eta ungui çadutçala. Amen.

\section{L'auteur de l'ouvrage au lecteur}

L'un des biens les plus grands que puisse posséder l'homme (Ami dévot) est l'oraison, laquelle consiste à élever son âme vers Dieu. Pour cela, sans prêter nulle attention aux allégations de quiconque, ou à ce qui pourrait être dit, je présente sous vos yeux cette doctrine. J'ai vraiment entendu et je sais que certains méprisent mon parler, et que d'autres préfèreraient la langue de leurs contrées : mais je supporterai mieux les reproches d'avoir écrit dans la langue de mon pays, que les louanges reçues si j'avais écrit autrement. Pour cette raison que nul ne s'étonne si je n'use pas d'une langue mélangée, mais que chacun utilise ce livre dévotement pour son propre bénéfice. Voilà mon intention.

Enfin, là où vous trouvez la lettre $\mathrm{H}$ dans le calendrier des fêtes, il s'agira d'une fête du tiers ordre; la lettre F, une fête de l'ordre de saint François ; les autres fêtes non signalées, chacun les apprend de l'église dans son pays. Que Dieu vous donne la grâce du bien-être, et qu'il vous préserve. Amen.

\section{AXULAR}

Avertissement au lecteur en tête d'Axular en préambule de Guero (1643) :

\section{IRACURTÇAILLEARI}

Egun batez, compaiñia on batean, euscaldunic baicen etcen leccuan nengoela, eccarri çuen solhasac, içan cen perpausa, etçuela deusec ere hanbat calte eguiten arimaco, eta ez gorputceco ere, nola eguitecoen gueroco vtzteac, egunetic egunera, biharretic biharrera luçatceac. Eta on çatequeiela, gauça huneţ̧az liburu baten, euscaraz, guztiz ere euscararic baicen etciaquitenentçat, eguitea; 
eta hartan, guero dioenac, bego dioela eracustea, compaiñia berean galdeguin cen berehala, ea nori emanen ceican liburuaren eguiteco cargua. Eta bertce guztien artetic, hasi ceizquidan niri neroni aditcera emaiten, lehembician kheinuz eta ayeruz, eta guero azquenean, clarqui eta aguerriz, nic behar nituela, eguiteco hartan escuac sarthu. Ordea nola ezpainintcen neure buruaz fida, desencusatu nintcen ahal beçanbat. Baiña alferric, ceren hain cinez eta batetan lothu ceisquidan, non ezetz erraiteco bide guztiac, hertsi baitcerausquidaten. Eta hala deliberatu nuen, buru-eragotz carri beçala, liburutto baten, bi partetan partituric, guero, hunen gaiñean eguitera.

Eta nahi nituzqueyen bi parteac elccarrequin, eta batetan athera. Baiña iccussiric cein gauça guti edireiten den euscaraz esquiribaturic, gogan behartu naiz eta veldurtu, eztiren bideac asco segur eta garbi, baden bitartean cenbait trabu edo behaztopa harri. Eta halatan hartudut gogo, lehenbicico parte hunen, lehenic venturatçeco, eta berri iaquitera beçala aitcinerat igortceco. Hunec cer iragaiten den, cer beguitarte içaiten duen, eta nor nola mintço den, auisu eman diadaçan. Guero auisu haren arauaz ethorquiçunerat gouernatceco : Eta bi garren partearen camporat atheratceco, edo barrenean guelditceco eta estaltceco.

Badaquit anhitzec miretsicoduela eta edirenen arrotz eta estraiñio, ni lan huni lotcea. Ceren anhitz içan baita orainocoan, eta baita orai ere, ni ez beçalacoric, ni baiño hunetaco gai agoric, eta ançatsu agoric, ezpaitute guztiarequin ere, orainocoan, hunelaco materiatan, hunela ausartciaric eta escu dantciaric hartu. Baitirudi ecen asco behar liçatequeyela arraçoin haur ene guibelatceco eta gueldi aracitceco ere. Baiña ene contra dela dirudien arraçoin hunec beronec, ni esportçatcen eta aitcinatcen nau, hunec bihotz emaiten deraut, haur edireiten dut nic neure alde eta fabore, ceren enseiucarrean beçala eguiten diren lehenbicico obrèc eta enseiuec, cembait hutz eta falta içanagatic ere, badirudi ecen, ceren lehenac diren, barccaquiçun direla, eta bat bederac disimulatceco, ez iccussi iduri eguiteco, eta are desencusatceco dituela.

Badaquit halaber ecin heda naitequeyela euscaraco minçatce molde guztietara. Ceren anhitz moldez eta differentqui mintçatcen baitira euscal herrian. Naffarroa garayan, Naffarroa beherean, Çuberoan, Laphurdin, Bizcayan, Guipuzcoan, Alaba-herrian, eta bertce anhitz leccutan. Batac erraitendu behatcea, eta bertceac so eguitea. Batac haserretcea eta bertceac samurtcea. Batac ilquitcea, bertceac ialguitea. Batac athea, bertceac bortha. Batac erraitea, bertceac esatea. Batac iracurtcea, bertceac leitcea. Batac liscartcea, bertceac ahacartcea. Batac hauzoa, bertceac barridea. Batac aitonen semea, bertceac çalduna. Finean bat bederac bere guisara, ançura eta moldera. Eztituzte euscaldun guztiec legueac eta azturac bat, eta ez euscarazco mintçatcea ere, ceren erresumac baitituzte different.

Bada esquiribatceaz denaz beçan batean ere ez naiz eguiteco gabe. Ceren bada hunetan ere differentcia. Batac esquiribatcendu chehero, bertceac gehero. Batac chedea, bertceac gedea. Batac ichilik, bertceac igilik. Batac lachoa, bertceac lajoa. Batac choil, bertceac, joil. Batac quecho, bertceac quejo. Batac chuchen, bertceac, jujen. Eta hunela bada, bertceric ere cembait hitz, batac eta bertceac, norc bere herrico edo erresumaco arauaz diferentqui esquiribatcen baitituzte.

Ordea ceren ezpaitira hamar-bat hitz edo baicen, hunela differentqui, eta bi aldetara esquiribatcen direnak : halatan nic ere cembait aldiz esquiribatucoitut 
alde batera liburuan barrena, eta bertce aldera liburuaren bazterrean, in margine: bat bederac cerbait contentamendu duen amoreac gatik.

Finean esquiribatce hunen gaiñean, diot ecen, nola latinac bi, $i$, eta bi, $v$, eguiten baititu bat eta hartcen batenţ̧at : Adjicio, Conjicio, Vultus, Vulnus. Eta Espaiñolac ere bi L, eguiten baititu bat, llamo, lloro: hala euscarac ere bi, $t$, eguiten dituela bat, ttipia, ttipittoa, guiçonttoa, haurttoa. Ceren esquiribatcera chipia, chipitchoa, guiçontchoa, haurtchoa ezta ongui heldu, euscaraz ongui mintçatcen direnen artean.

Baiña ceren comunzqui, hala esquiribatcea, nola mintçatcea, nori berea iduritcen baitçaica hoberenic eta ederrenic : eta ene haur ezpaita çurea beçala : ez, othoi, hargatic arbuya eta ez gaitz erran. Hunetçaz content ez paçara, eguiçu çuc ceure moldera, eta çure herrian vsatcen eta seguitcen den beçala. Ceren ez naiz ni hargatic beccaiztuco, eta ez mutturturic gaitzez iarrico. Aitcitic haur da nic nahi nuqueyen gaucetaric bat, ene enseiu appur hunec quilica cinitçan eta guticia, enseiu hobeago baten eguitera eta ene hemengo falten ere erremediatcera. Ceren halatan, ez liçateque euscara hain labur, escas eta ez hertsi, nola munduac vste baitu, eta baitaduca, dela.

Orai badirudi euscarac ahalque dela, arrotz dela, eztela iend'artean ausart, entregu, bithore eta ez trebe. Ceren are bere herricoen artean ere, ezpaitaquite batçuec, nola esquiriba, eta ez nola iracur.

Baldin eguin baliz euscaraz hanbat liburu, nola eguin baita latinez, franceses, edo bertce erdaraz eta hitzcunţ̧az, hec beçain aberats eta complitu içanen cen euscara ere, eta baldin hala ez pada, euscaldunec berèc dute falta eta ez euscarac.

Eztut liburutto haur letratu handienţ̧at eguiten. Eta ez choil, deus eztaquitenentçat ere.

Ez eta, eztitut bethiere, eskritura saindua eta doctoren erranac ere, hitcez hitz euscarara bihurtcen. Ceren euscara eta bertce hitz cunţ̧ac diferent baitira. Ordea ezta ez handic seguitcen gaixtoago dela euscara. Aitcitic badirudi ecen bertce hitz cuntça eta lengoaya comun guztiac bata bertcearequin nahasiac direla. Baiña euscara bere lehenbicico hastean eta garbitasunean dagoela.

Baiña euscara eta euscararen minçatceco eta esquiribatceco moldeac eta differentciac vtcirik : ceren hec açala eta lorea beçala baitira : har eçaçu, liburutto hunen fruitua, barreneco mamia : haur dasta eçaçu, haur escuzta eçaçu, iracurtcen duçula, ez lehiaz, ez gainguiroqui eta ez arbuiatceco contuan ere. Baiña intencione on batequin, ceurea, ceurc eguina baitcendu beçala, Eta baldin halatan eta orduan, bat ere goçoric edo çaphoreric edireiten badioçu, ceren hura guztia iaincoaganic heldu baitateque, eta ez eneganic faltaric baicen, hari esquerrac errenda iatçotçu, eta nitçaz ere othoitz eguiteaz, arren othoi, orhoit çaiteci.

\section{Au lecteur}

Un jour, alors que je me trouvais dans une compagnie agréable, composée uniquement de Basques, la conversation apporta le sujet, et le propos vint, que rien ne faisait plus de mal à l'âme, et même au corps, que le recul de l'accomplissement des devoirs, leur remise à plus tard de jour en jour, et de lendemain en lendemain. Et qu'il serait probablement bon de faire un livre en basque sur ce thème, destiné en particulier à ceux qui ne savent que le basque, et d'y montrer 
que celui qui dit 'plus tard' dit 'jamais'. Et parmi tous les présents, c'est à moi que l'on commença à faire comprendre, d'abord par signes et par allusions, puis, à la fin, clairement et ouvertement, qu'il me fallait prendre en mains cette tâche. Toutefois, comme je n'avais guère confiance en moi, $\mathrm{j}$ 'essayais le plus possible de me faire excuser. Mais en vain, car on s'efforça si sincèrement et unanimement de me convaincre, qu'on me ferma toutes les voies de refus. Et ainsi je décidai, comme un défi pour mon esprit ${ }^{8}$, de faire ce livre, en le divisant en deux parties.

Et j'aurais voulu publier ces deux parties ensemble et en même temps. Mais voyant que si peu de choses avaient été écrites en basque, je me suis inquiété et j'ai pris peur que la route ne soit pas assez sûre et dégagée, et qu'il n'y ait sur le chemin quelque obstacle et pierre de trébuchement. Et ainsi, j'ai décidé d'aventurer d'abord cette première partie, et de l'envoyer par devant en manière d'éclaireur. Afin qu'elle m'avise de ce qu'il advient, de l'accueil qu'elle reçoit, et de la manière dont on en parle. De façon à agir en fonction de cet avertissement par la suite : ou bien en publiant cette seconde partie, ou bien en la gardant par-devers moi, et en l'y celant.

Je sais que beaucoup s'étonneront et trouveront insolite et étrange que j'entreprenne une tel travail. Car ils ont été nombreux jusqu'ici, et ils le sont encore, ceux qui, différents de moi, plus capables et plus compétents que moi pour cette tâche, n'ont pas eu malgré tout jusqu'à maintenant semblable audace et hardiesse en une telle matière. Il semblerait que cette raison devrait être suffisante pour me retenir et m'arrêter. Mais cet argument qui semble m'être contraire, m'encourage et me pousse à aller de l'avant, il me donne du cœur, il est en ma faveur et plaide pour moi, car, quand bien même les œuvres et tentatives que l'on fait comme à l'essai contiennent quelques fautes et faiblesses, il semble que celles-ci, parce qu'elles sont les premières, sont pardonnables, et que chacun est en mesure de les dissimuler, de les ignorer, et même de s'en faire excuser.

Je sais aussi qu'il m'est impossible d'atteindre toutes les manières de parler basque. Car on parle différemment et de beaucoup de manières diverses dans le pays basque : en Haute-Navarre, en Basse-Navarre, en Soule, en Labourd, en Biscaye, en Guipuscoa, dans le pays d'Alava, et dans biens d'autres endroits. L'un dit behatcea l'autre so eguitea. L'un dit haserretcea, l'autre samurtcea. L'un dit ilquitcea, l'autre ialguitea, l'un dit athea, l'autre bortha, l'un dit erraitea, l'autre esatea, l'un dit iracurtcea, l'autre leitcea, l'un dit liscartcea, l'autre ahacartcea, l'un dit hauçoa, l'autre barridea. L'un dit aitonen semea, l'autre çalduna. Enfin, chacun à son gré, à sa façon et à sa manière. Tous les Basques n'ont pas les mêmes lois et usages, ni le même mode de parler basque, car ils appartiennent à des royaumes différents.

Et en ce qui concerne l'écriture également je ne suis pas sans travail. Car en cette matière aussi il y a des variations. L'un écrit chehero, l'autre gehero. L'un chedea, l'autre gedea. L'un ichilic, l'autre igilic. L'un lachoa, l'autre lajoa. L'un choil, l'autre joil. L'un quecho, l'autre quejo. L'un chuchen, l'autre jugen. Et ainsi encore d'autres mots, que les uns et les autres écrivent différemment, chacun selon les us de son pays ou de son royaume.

Toutefois, comme il n'y guère plus de dix mots qui diffèrent ainsi et s'écrivent de deux façons, parfois je les écrirai moi aussi d'une manière à l'intérieur du texte, et de l'autre en bordure, in margine : afin que chacun puisse avoir quelque satisfaction. 
Enfin, relativement à cette question d'écriture, je déclare que de même que le latin prend et fait un de deux $\boldsymbol{i}$ et deux $\boldsymbol{v}:$ Adjicio, Conjicio, Vultus, Vulnus; et que l'espagnol également fait un de deux $l$ : llamo, lloro, ainsi le basque également fait un de deux $\boldsymbol{t}$ : ttipia, ttipittoa, guiçonttoa, haurttoa. Car si l'on écrit chipia, chipichoa, guiçonchoa, haurchoa, cela n'est pas bien reçu chez ceux qui parlent bien basque.

Mais comme communément en matière d'écriture et de parler, chacun trouve sa propre manière la meilleure et la plus belle, et comme celle qui est la mienne ici n'est pas semblable à la vôtre, de grâce ne la méprisez pas et n'en dites pas de mal. Si vous n'en êtes pas content, faites selon votre façon et conformément à la manière qu'on use et suit dans votre pays. Car je ne m'en serai pas jaloux et ne m'en montrerai pas offensé. Au contraire, l'une des choses que je souhaiterais est que ce petit essai vous incite et vous motive à en faire un autre meilleur que celuici et à corriger mes fautes. Car si l'on avait procédé ainsi, le basque ne serait pas aussi limité et pauvre, ni aussi restreint, que les gens croient et tiennent qu'il est.

Il semble aujourd'hui que le basque soit timoré et inexpérimenté, qu'il n'est pas audacieux, assuré, compétent, ni exercé en public. Car, même parmi ses locuteurs, certains ignorent comment l'écrire et le lire.

S'il avait été écrit autant de livres en basque qu'il en a été fait en latin, en français ou dans d'autres idiomes étrangers et langues, le basque aurait été aussi riche et accompli que ces langues, et s'il n'en est pas ainsi, la faute en revient aux Basques eux-mêmes, et non à la langue basque.

Je n'écris pas ce petit livre pour les lettrés éminents, ni seulement pour les ignorants qui ne savent rien.

Et je ne traduis pas non plus toujours l'écriture sainte et les dires des docteurs mot à mot. Car le basque et les autres langues sont différents. Mais il ne suit pas de ceci que le basque est plus mauvais. Au contraire, il semble que les autres langues et idiomes vulgaires sont mélangés les uns avec les autres, alors que le basque demeure dans son état et sa pureté d'origine.

Mais laissant de côté la langue basque et les variations et manières diverses de l'écrire et de la parler, car il ne s'agit là que de la surface et de la fleur, prenez le fruit de ce livre, sa chair intérieure : goûtez-le, soupesez-le tandis que vous le lisez, ni en vous pressant, ni de façon superficielle, ni dans le dessein de le rejeter, mais dans une bonne intention, comme s'il était vôtre et que vous l'aviez fait. Et si vous lui trouvez alors quelque douceur et saveur, comme tout ceci lui sera venu de Dieu, et non de moi, sinon les fautes, rendez-lui grâces, et, souvenezvous, je vous en prie, de prier pour moi également.

\section{ARGAIÑARATZ}

Avis aux dévots en tête du Devoten breviarioa (1665):

\section{DEVOTEI ${ }^{9}$}

Deuotac, çuena beçala, breuiariotcho hau, çuei heldu çaitçue deuotac çareten maneran deuoten icenarequin, baiñan deuotago oraiño çuen deuot içatea errenda dieçaçuentçat, Çazpi princesa sainduen bicitce deuotac escolatçat aitci- 
nean presentatcen darozquitçuela ceinac bere errethauletan ikhusico tutçuen beçala, hala duqueçue. ${ }^{10}$

Matutiñetan, Sant Elizabeth, ceiña gauerdi gucietan jaiquitçen baitçen errethaula batean beçala Ifernuco gau ilhun eta hango damnatuen penen meditatcerat.

Priman, Santa Radegonda, ceiña, goiz guciez eguna descubritcen hasten cenean berehala, baiçagoen meditatcen ceruco seculaco eguna haren errethaulan ikhusico duçuen beçala.

Tercian, Santa Clotilda, ceiña gogoaren bortchaz bestitcen baitcen erreguiña içan arren, soin berreguiñ eta aberatsez : huntaracotz contemplatcen çuela errethaula batean Maria Egipciana bere iracharloez" [texte : icharrloez] bestitua desertuan bici içan cen beçala berrogoi eta çazpi urtez, haren errethaulan agueri den maneran;

Sextan, Santa Cristina, ceiña bestitu çen beçain sarri munduco obra gucietaric apartatua espiritualei lotcen baitcitçaien; huntaracotz baçaducan bere beguien aitcinean errethaula bat, Maria Madalenarena eta Martarena, haren errethaulan ikhusico duçuen beçala.

Nonan, Sant Eleonor, ceinac bere othurunçen hartcean baitçaducan [texte : baitcaducan] bere aitcinean errethaula bat Jesu Christo gure salbatçaillearena ceinari burreu batec presentatcen ciotçala ${ }^{12}$ khelder eta miñagrea haren errethaulan ikhusico duçuen maneran.

Vesperetan. Sant Helena, ceina bere hill orenaren contemplatcen baitcen bethi occupatua, huntaracotz beguien aitcinean çaducala errethaula bat ceiñetan aingueru batec erhiaz beçala eracusten baitcioen erroloia [texte : erroloio] ${ }^{13}$ baten marcan bere bicia, hiltceraco vesperan çuela, haren errethaulan agueri den beçala ;

Completetan Lorrenaco Margarita, Alençõgo duqueça ceinac bere burua bici celaric hiltçat baitçaducan, huntaracotz bere beguien aitcinean çaducala errethaula bat ceinetan pintaraci baitçuen bere burua hilla içan baliz beçala gatabute batean, ikhusico duçuen beçala haren errethaulan.

Deuotac, imitaçaçue saindu handi hauc bere bicitce sainduetan, eta orduan çaratezquete icenez eta obraz deuotac.

\section{Aux dévots}

Dévots, ce petit bréviaire vient à vous comme étant vôtre, avec l'appellation des dévots tout comme vous même êtes dévots, mais présentant devant vous à titre d'enseignement, afin de rendre plus fervente votre dévotion, les vies dévotes de sept princesses, que vous trouverez ainsi que vous les verrez dans leur gravu$\mathrm{re}^{14}$. Il en sera ainsi.

Aux Matines, sainte Elisabeth, laquelle tous les minuits se levait, comme dans une gravure, afin de méditer les peines des damnés et des nuits ténébreuses de l'enfer.

A Prime, sainte Radegonde, laquelle tous les matins, lorsque le jour commençait à se découvrir, aussitôt restait à méditer sur le jour de l'éternité céleste, ainsi que vous le verrez dans la gravure. 
A Tierce, sainte Clotilde, laquelle bien qu'elle fût reine se vêtait contre son gré des robes les plus élégantes et riches; contemplant pour cela dans un tableau Marie l'Egyptienne, vêtue de fougères ${ }^{15}$ ainsi qu'elle vécut durant quarante sept ans dans le désert, comme il paraît dans la gravure la représentant.

A Sexte, sainte Christine, laquelle, aussitôt qu'elle s'habillait, s'écartant de toutes les affaires terrestres, s'attachait aux tâches spirituelles; pour cela elle tenait devant ses yeux un tableau, celui de Marie Madeleine et de Marthe, ainsi que vous le verrez dans sa gravure.

A None, sainte Eléonore, laquelle lorsqu'elle prenait ses repas, tenait devant ses yeux un tableau de notre sauveur Jésus-Christ, dans laquelle un bourreau lui présentait le fiel et le vinaigre, ainsi que vous le verrez dans sa gravure.

Aux Vêpres, sainte Hélène, laquelle était toujours occupée à contempler l'heure de sa mort, tenant pour cela devant ses yeux un tableau où un ange lui montrait, comme avec le doigt, dans la marque d'une horloge, que sa vie était à la veille ${ }^{16}$ de sa mort, ainsi que vous le verrez dans sa gravure.

Aux Complies, Marguerite de Lorraine, duchesse d'Alençon, laquelle se tenait pour morte alors qu'elle vivait, tenant pour cela devant ses yeux, un tableau où elle s'était faite peindre dans un cercueil comme si elle était morte, ainsi que vous le verrez dans sa gravure.

Dévots, imitez ces anges dans leurs saintes vies, et alors vous serez dévots, de par votre nom et de par vos œuvres.

\section{TARTAS}

Avertissement au lecteur de Tartas en tête de Onsa hilceco bidia (1666) :

\section{IRACCVRTCALIARI}

NEVRE adesquidia, igarén vdan egun batez nangoela çuhaincé batén itçalbian neuré orenen errayten ninçala, loac harturic, eguindut neuré loan ametz handibat eta misteriosbat, iduriţ̧en çautan neuré ametsian, iccusten niala guiçon eta emazté [texte : einazté] tropelabat goiti çelurat igaiten eta bertçé tropela bat oraino handiagoric beheiti ifernurat ioaiten eta erorten [texte : eroten], gendé hec consideraturic batçiac gora, bertçiac behera ioaiten çirela, oihu eguindut eta heiagora orori, çer çen causa, edo çergatic batçiac goiti bertçiac beheiti ioaiten çiren : bere hala heldu da, botzbat çelutic eta emandu errapostu botçac ené oihia, eta heihagora ençunic, gende hetaric partebat goiti çelurat ioaiten çela, çeren beré herioaz, eta bere hilçiaz mundu hontan ordu honetz orhituric, eta herioac beccatu mortalic bateré gaberic gratiazco estatian atrapaturic, lurretic partitcen baitçiren; eta berçé parté guehiena beheiti ifernurat ioaiten çirela, çeren beré herioaz eta beré hilçiaz asqui ordu honéz orhitu faltaz, gratiazco estatutic campoan, herioac beccatu mortaléz betheric atrapaturic, lurretic partitcen baitciren hargatic cirela galdu, eta damnatu.

Loac eta ametsac, eta ametsaren errapostiac içituric, eta lotsaturic, iratçartu ninçan, eta hartu lumá escúra euscaldunen fauoretan euscaraz porogatçeco, onsa hilçeco bidia dela, herioaz, eta hilçiaz ardura orhitçia eta salbatçeco eztela bidé hoberic mundian. Edirenen duçu laur capitulu ené liburian, lehenian porogat- 
cendut paganoen erranaz, bi garrenian, legué çaharreco escritura saindiaz; hirur garrenian legué berriaz, eta eliçaco doctor saindiéz, laur garrenian laur arraçoin differentéz, onsa hilçeco bidia dela herioaz [texte : herrioaz], eta hilçiaz orhitcia.

Ené triuaillu appurrac eztu meritatçen çuc phena har deçaçun haren iraccurtçeco, baina çure salbamendiaren amorioac, eta desirac, eman derauté coraie, haren camporat idoquiteco, eta hari arguiaren emaiteco.

Ené euscara eta lengagia eztaquit aprobatia içanen denéz, bai, ala ez, Badu orotaric cerbait, çuberoac, Bassanauarrec, eta lapurdic emandrauco çerbait, baina ez oro; arueneguin dut neuré pieça pobria, hanco lengagia ezpada asqui eder, hanco euscarac, du oguena, eta ez euscaldunac.

$$
\text { (... })^{17}
$$

Deus honic ené librian ediren badeçaçu, ohoria, eta laudorioa emaçu Iincoari, eta ez niri, ezta niganic heldu hontarçuna, baina bai, Incoaganic, omne datum optimum, \& omne donum perfectum de sursum est, descendens à patre luminum. Iacob. I.

Ezpada deus honic, erraçu libriaren, eguiliac baçiala borondatia onsa eguiteco, eta lanaren mensa, eta falta, reparatçen eta desencusatçen diala, languiliaren, intentioné, eta borondaté honac, voluntas dantis reparauit paruitatem dati.

Ohoratçen baduçu çuré approbationiaz ené pieça mendria, eta eguiten çure arimaren profeitia, haren Iraccurţ̧ian, norc çer pagu, eta recompensu handiagoric nahidu mundian; Iincoari othoy eguinendut biçi niçan egunetan çure hilçiaz lurrian orhoituric, sainduqui biçiric, eta sainduqui hilic, mundu hontaric landan, çeluco resuma eternala eman diçaçun. Amen.

\section{$\mathrm{Au}$ lecteur}

Mon ami, alors qu'un jour, l'été dernier, je me trouvais à l'ombre d'un arbre à lire mes heures, m'étant endormi, j'ai fait dans mon sommeil un rêve grand et mystérieux; il me semblait que je voyais dans mon rêve une troupe d'hommes et de femmes montant au ciel, et une autre troupe, encore plus grande, descendant et chutant en enfer, et, considérant ces gens, les uns allant vers le haut, les autres vers le bas, j'ai crié, et poussé des clameurs : quelle était la cause de ceci et pourquoi les uns allaient vers le haut, les autres vers le bas; aussitôt, vint du ciel une voix qui, ayant entendu ma clameur et mon cri, répondit qu'une partie de ces gens montait au ciel parce qu'ils avaient quitté la terre s'étant souvenus assez tôt en ce monde de leur mort et de leur trépas, et la mort les ayant attrapés en état de grâce sans qu'ils aient aucun péché mortel, et que l'autre plus grande partie descendait en enfer, parce que, faute de s'être souvenus suffisamment tôt de leur mort et de leur trépas, ils avaient quitté la terre hors de l'état de grâce et la mort les ayant attrapés entièrement souillés de péchés mortels, et que pour cette raison ils s'étaient perdus et damnés.

Épouvanté et effrayé par mon sommeil, mon songe et la réponse de mon rêve, je me réveillai, et pris la plume à la main pour prouver au bénéfice des Basques que la manière de bien mourir consiste à se rappeler fréquemment de la mort, et qu'il n'existe pas de voie meilleure en ce monde pour se sauver. Vous trouverez quatre chapitres dans mon livre; dans le premier, je prouve par les dires des 
païens, dans le second, grâce à la sainte écriture de la vieille loi, dans le troisième en vertu de la loi nouvelle et des saints docteurs de l'église, dans le quatrième au moyen de quatres différentes raisons, que la manière de bien mourir consiste à se rappeler de la mort et du trépas.

Mon modeste travail ne mérite pas que vous preniez la peine de le lire, mais le souhait et le désir de votre salut m'ont donné le courage de le rendre public et de lui donner le jour.

J'ignore si mon basque et mon langage sera ou non approuvé. Il tient quelque trait de partout. La Soule, la Basse-Navarre et le Labourd lui ont donné quelque chose, mais point tout. J'ai écrit ma pauvre pièce à Aroue. Si la langue du lieu n'est pas assez belle, la faute en revient au basque de l'endroit, et non au locuteur.

\section{(...)}

Si vous trouvez quelque chose de bon dans ce livre, attribuez-en l'honneur et les éloges à Dieu, et non à moi; le bien ne vient point de moi, mais de Dieu; omne datum optimum, \& omne donum perfectum desursum est, descendens a patre luminum. Iacob. I.

Si vous n'y trouvez rien de bon, dites que l'auteur du livre avait la volonté de bien faire, et que ses bonnes intention et volonté excusent et réparent le défaut et l'insuffisance de travail, voluntas dantis reparavit paruitatem dati.

Si vous honorez ma modeste pièce de votre approbation, et que vous en tirez profit pour votre âme en la lisant, qui voudra plus grande récompense et rétribution en ce monde? Je prierai Dieu durant les jours que je vivrai, afin que, vous étant souvenu de votre mort sur cette terre, ayant vécu saintement et étant mort saintement, il vous donne après ce monde, le royaume éternel. Amen.

Avertissement au lecteur de Tartas dans Arima penitentaren occupatione devo$\operatorname{tac}(1672)$ :

\section{IRACCURTÇALIARI}

Neure adesquidia, igaren urthian eguin dut eta eçarri arguira libruto bat euscaraz, çoignen icena baita Onsa Hilceco Bidia eta comprenitcen baititu onsa hilceco moyenac, han agueri den beçala. Gueroz aurthen Iincoaren aiutu saindiarequila battian eguin dut eta nahi camporat idoqui bertce pieçato bat, çoignen handitarçuna oro cerraturic baitago escu bat paperen voluman. Han iccussico duçu hirur princessa ederric, çoin baitira orationia, barura eta amoyna; halaber goix-arratzez eguin behar duçun [texte : daçun] concenciaren examena eta Andere honaren leitharignac. Hayen iraccurtcian eguiten baduçu çure arimaren profeitia eta Iincoari othoy eguiten obra honen Autoragatic, uqhenen drauçut mila obligatione eta Iincoac emanen drauçu celian çure penaren recompensia.

\section{$\mathrm{Au}$ lecteur}

Mon ami, l'an dernier j'ai écrit et mis au jour un petit livre en basque, dont le nom est Onsa Hilceco Bidia, et qui indique les voies pour bien mourir, comme cela peut s'y constater. Depuis, avec la sainte aide de Dieu j'ai écrit cette année 
et veux publier une autre pièce, dont la dimension se trouve tout entièrement contenue dans le volume d'une poignée de papier. Vous y trouverez trois belles princesses, qui sont l'oraison, le jeûne et l'aumône; ainsi que l'examen de conscience que vous devez faire matin et soir et les litanies de la bonne Mère. Si leur lecture est profitable à votre âme, et si vous priez Dieu pour l'auteur de cette œuvre, $\mathrm{j}$ 'aurai envers vous mille obligations et Dieu vous donnera au ciel la récompense de votre peine.

\section{GASTELUÇAR}

Avis au lecteur de Gasteluçar en tête de Eguia catolicac (1686) :

\section{ABISUA}

Jainkoa, gure errege bezala, bethi goizetik arratseraiño ungi egiten hari zaikunaz gerostik, justu da guk ere ohoratzeko, eta maitatzeko gure ezagutzak egin diozogun. Kreatu gaitu, nezesarioki haren begietan bizi behar dugu, eta irabaz detzakegu memento gustiez khoroa eternalak, baldiñ ungi egiten badugu gure egiñbidea. Bertze gauza gustiak eztire banagloriarik baizen; beraz, gure hartharik handiena behar da, leialtasun, ohore, eta amudio Jainkoarentzat.

Denbora hautan, hañitzek hañitz liburu eder argira eman tuste; ezta, bada, hau bertzeak baño ederragoa; bañan nola berze gauzetan bezala, debozionean gustu diferenteak baitire, iduritu zait hañitz deboten artean, batzuek huntan gustu hartuko dutela, gustiz mariñel debotek; eta hek prinzipalki konsideraturik, deliberatu dut liburu hunen egitera ; erranen baitute batzuek, bizi zenean orhoitu zen bere herriaz, eta ez zitzaion ahantzi hiltzerakoan, bere señalleak emanik joan baita. Ezen nola plazer hartzen baitute itsasoan latinez Elizako himnoen kantatzeaz, atsegin gehiago izanen dutela ${ }^{18}$ himno beren ezkaraz errateaz, aire berean ezkaraz ematen tut; eta gaiñerako bersuen airea komunzki gustiek badakite.

Zazpi parte ditu : 1) da giristiñoaren eginbidea ; 2) Jesus Kristoren debozionea; 3) Aldareko Sakramendu sainduarena; 4) Andredena Mariarena; 5) gizonaren lau fiñak; 6) Hañitz kondizionetako jendeentzat oraziñoak; 7) Salbamenduaren egiteko, eta Sakramenduen ongi errezibitzeko jakin behar den doktrina.

Batzuek hañitz oraziñoen errateko usantza dute, konsideratu gabe zer erraten duten. Ezta hori oraziñoen erratea, ez Jainkoari plazer egitea, bañan bai bere buruari atsegin egitea, eta usatu tuen oraziñoetako penetarik bere espirituaren libratzea. Hirur gauza bethi konsideratu behar liratezke : nor mintzo den, nori eta zertzaz. Gizona da mintzo dena, Jainkoari mintzo zaio, eta salbamenduaren egiteko handiaz mintzo zaio.

\section{Avis}

Puisque Dieu, en tant qu'il est notre roi, nous fait constamment du bien du matin jusqu'au soir, il est juste que nous aussi lui manifestions notre témoignage d'hommage et d'amour. Il nous a créés, nécessairement nous devons vivre sous ses yeux, et à chaque instant nous pouvons gagner des couronnes éternelles, si nous accomplissons bien notre devoir. Toutes les autres choses ne sont que vanités; aussi notre plus grand souci doit être la fidélité, l'honneur et l'amour envers Dieu. 
Ces temps-ci, beaucoup ont publié beaucoup de beaux livres, celui-ci n'est pas plus beau que les autres; mais comme il existe des goûts différents en matière de dévotion ainsi que dans les autres choses, il m'a semblé que, parmi de nombreux dévots, certains, en particulier les marins dévots, apprécieront celui-ci. Et c'est en ayant principalement ces derniers à l'esprit que j'ai décidé d'écrire ce livre. Ainsi certains diront : lorsqu'il vécut, il se souvint de son pays, et il ne l'oublia pas non plus à l'heure de mourir, car il est parti en laissant son empreinte. En effet, comme les marins prennent plaisir à chanter en latin les hymnes de l'église lorsqu'ils sont en mer, je les traduis en basque sur le même air, pensant qu'ils auront encore plus de plaisir à les dire en basque. Quant aux airs des autres vers, d'ordinaire, tout le monde les connaît.

Le livre a sept parties : 1) le devoir du chrétien; 2) la dévotion envers Jésus Christ; 3) celle envers le saint sacrement de l'autel; 4) celle envers la Vierge Marie; 5) les quatre fins de l'homme; 6) les oraisons destinées aux gens de toutes conditions; 7) la doctrine qu'il faut savoir pour bien recevoir les sacrements et assurer son salut.

Certains ont l'habitude de dire beaucoup d'oraisons, sans considérer ce qu'ils disent. Ce n'est pas là dire les oraisons, ni faire plaisir à Dieu, mais se faire plaisir à soi même, et libérer son esprit des peines des oraisons auxquelles on est habitué. Il faudrait toujours considérer trois choses : qui parle, à qui, et de quoi. C'est l'homme qui parle, il parle à Dieu, et il lui parle de l'obligation importante du salut. 


\section{Notes relative à l'annexe}

1. Nous restituons dans ce recueil le texte basque dans sa forme de publication originale ou, à défaut, la plus ancienne que nous ayons pu rencontrer, sauf pour Eguia catolicac de Gasteluçar, pour lequel, pour des raisons matérielles, la seule source a été l'édition d'Akesolo (1983). Pour le texte de Liçarrague, nous avons employé l'édition, conforme à l'original, de la version Linschmann \& Schuchardt (1900) reproduite en fac-similé par l'Académie de la Langue basque (1990). Pour l'adresse aux Basques de la première édition (1617) de Dotrina christiana de Materre, laquelle est perdue, nous avons utilisé le texte de la deuxième édition de 1623, qui la reproduit. Pour le Manual devotionezcoa d'Etcheberri, la version en facsimilé de l'édition de 1669 publiée en fac-similé chez Hordago en 1978 a servi de base. Pour le prologue d'Argaiñaratz, j'ai reproduit le texte, certainement reconstruit, de Vinson dans son édition de 1910, mais en restituant également en note celui de la copie manuscrite tardive de l'ouvrage qui lui a probalement servi partiellement de modèle (cf. note infra). Enfin, pour les textes de Tartas, la version en fac-similé de Onsa hilceco bidia et celle -reprise de l'édition originale- de Arima penitentaren occupatione devotac, toutes deux offertes par Altuna à côté de ses éditions critiques (1995, et 1996). Le texte de Onsa hilceco bidia dans la publication en fac-similé d'Altuna est une reproduction de celui publié par la RIEV (1907-1911), conformémént à l'original.

De façon générale nous n'avons pas modifié le texte source dans le recueil, sauf pour l'ancienne graphie $f$ des $s$, et pour les voyelles écrites avec la tilde, qui ont été actualisées. En dehors de ces cas, lorsque le texte source est modifié, nous indiquons immédiatement après le mot modifié et entre crochets, la forme apparaissant dans celui-ci.

2. Le texte ne laisse aucun doute, et nous ne pensons pas indispensable de le modifier. Altuna dans son édition (1981 : 48) préfère corriger en raison du peu de signification qu'a le vocable fiñean ici, et propose fuiñean lit. 'dans le cerveau'. Toutefois, l'emploi de ce terme dans ce contexte est inattendu, d'autant que buruan 'dans la tête'ou gogoan 'dans l'esprit' étaient disponibles puisque la métrique le permettait; au demeurant même en ce cas l'expression attendue est plutôt construite avec le verbe erabili.

3. Je traduis fiñean 'à la fin' sans changer le texte, et en supposant qu'il s'agit d'une cheville n'ajoutant rien au sens, ce qui n'est pas impossible chez Etcheberri qui présente d'autres exemples de cette facilité. Si l'on suivait Altuna dans sa correction (cf. note précédente) nous aurions : que le chrétien jour et nuit doit tourner dans son esprit (lit. cerveau).

4. Les oraisons doubles sont les prières qui se disent par répétition, comme les rosaires et les litanies. Contrairement aux autres prières, dites simples, Etcheberri ne les a pas mises en vers.

5. J'identifie le Beriñ du texte comme étant Michele Verino (en italien), dont les vers étaient utilisés dans les collèges avec ceux de Caton; M. Bataillon dans son ouvrage Erasme et l'Espagne indique : L'humanisme des collèges est tout imprégné de christianisme. Des distiques de Michel Verino ou de Caton, les débutants passent aux hymnes et aux oraisons de l'église avant d'aborder Térence. (p. 16). Cet auteur de vers latins de la fin du XV' siècle, mort à l'âge de dix huit ans (1487), est considéré comme un humaniste florentin. Cependant, il a été également parfois présenté comme un poète espagnol, sous le nom de Miguel Veri; il était natif des Iles Baléares (Menorca) qu'il aurait quittées dans son enfance pour l'Italie.

6. L'interprétation est peu sûre. Le terme partiada est utilisé par Etcheberri à deux autres reprises dans l'ouvrage pour signifier départ, dont une fois dans le contexte de la mort (1669:1,59): Hunez probetxa guintecen azquen demboretaco/Principalqui arimaren triste partiadaco (De cela tirons profit pour les derniers instants, principalement pour le départ final de l'âme). La seconde partie du premier livre du Manual a pour thème les fins dernières de l'homme.

7. L'ouvrage contient un second avertissement au lecteur, mais il correspond à la signalisation des fautes d'impression. Le texte, restitué ici dans une forme orthographique quelque peu actualisée, est un bel exemple d'esquive, à la limite de la prétérition :

Irakurzailleari abertimendua.

Irakurzaille debota obra hunen inprimatzean eginik zenbait falta liburu hunetan azkendu ahal lizate; ordea badaritzat hitz gaizki eskiribaturik edo berze gisazko faltarik edireiten duzunean, falta haren aitzineko eta ondoko hitzetarik liburuaren egileak persu hartan zer erran nahi duen errazki zure iuiamendu onak ezagutuko duela.

Avertissement au lecteur

Lecteur dévot, quelques fautes ont pu rester dans ce livre, après qu'elles aient été commises lors de son impression; mais il me semble que lorsque vous trouverez un mot mal écrit ou une faute d'une autre sorte, votre bon jugement reconnaîtra facilement à partir des mots précédant ou suivant le mot fautif, ce que l'auteur veut dire dans ce vers. 
8. Le texte basque (buru-eragotz karri beçala) est difficile à interpréter. Villasante traduit a modo de descargo.

Le suffixe carri correspond à un rôle sémantique d'effecteur, et la locution à laquelle il se joint associe le radical verbal eragotz 'jeter, secouer, projeter' dans les dialectes du nord, et le nom buru 'tête' interprétable ici au sens d'esprit. La traduction proposée interprète cette analyse, mais le résultat demeure hypothétique.

9. Je reporte le texte que Vinson restitue dans son édition de 1910. Il diffère sur certains points d'orthographe de celui qu'il avait donné dans le supplément à sa Bibliographie (1898: § 30, p. 552-559 dans l'édition de l'ASJU en un volume de 1983). En fait il semble bien qu'il s'agisse d'un texte reconstruit puisque Vinson indique : L'avis en prose qui est en tête du volume est extrêmement important : il ne nous a été conservé que par la plus imparfaite des deux copies. Il ajoutait à propos de sa transcription de la bibliographie : je ne garantis pas l'orthographe (p. 556). Les deux copies sont des copies manuscrites qui ont permis à Vinson de reconstituer certains passages manquant dans le seul ouvrage imprimé conservé. L'une de ces copies manuscrites fut, semble-t-il, offerte par Vinson à J. de Urquijo. Si tel est le cas, elle est visible au Centre Koldo Mitxelena de Saint-Sébastien, et elle est celle qui contient I'avis aux dévots, lequel n'aurait donc pas d'autre source. Par commodité, et en l'absence d'édition originale, j'ai suivi ici l'édition de 1910 de Vinson, sauf à propos des termes iracharloez et erreloia (voir notes infra).

Le texte manuscrit, qui modifie l'orthographe du modèle, est le suivant (la parenthèse en fin de mot indique une lettre manquante ou non lisible sur le microfilm en bout de page) :

DÉBOTEI.

Debotac çubena beçala, brebiariotcho hau cebei heldu çaitçue debotac çareten maneran Déboten jcenarequin, bainan debotago oraiño ceben debot içatea errendadieçaçuentçat, Cazpi princesa Sainduen bicitce debota esquolaçat aitçinean presentaçen darosquitçuela ceinac bere errethauletan ikhusico tutçuen beçalo, hala duqueçue

Matutinetan Sant Elisabeth Ceiña gauerdi guçietan jaiquitçen baiçen errethaula batian beçala ifernuco gau jllhun eta hang0 Damnatuen penen meditaçerat

Priman Santa redegonda Ceina gois gouciez eguna descubriçen hasten cenean berehala, baiçagoen meditatcen Ceruco seculaco eguna haren errethaulan ikhusico duçun beçala;

Terçian Sant Clotilda, ceina gogoaren borcha bestitçen baitçen erreguiña j̧̧an arren soin berreguiñ eta aberatsez : huntaracotç Contemplaçen çuela errethaula batian maria egipciana bere iracharloez bestitua desertuan bici içan Cen beçala berrogoi eta Saspy urtez, haren errethaulan agueri den maneran

Sextan santa Cristina, Ceina bestitu cen beçein sarri munduco, obra guçietaric apartatua espiritualei lotçen baitçitçaién huntaracotç baçaducan bere beguien aitçinian errathaulabat, maria madalenarena eta martarena, haren errethaulan ikhusico Douçuen bessala

Nonan Sant eleonor, ceinac bere othurunçen harcian baicaducan bere aitçinean errethaula-bat Jesu Christo gure salbatcaillearena Ceinari burreu batec presentaçen ciotçala khelder eta minagrea haren errethaula ikhuçico duçuen maneran.

Vesperetan Sant helena, ceina bere hill orenaren Contemplatcen baitçen bethi ocupatuba, huntaracotç beguien aitçinian çaducala errethaulabat ceinetan aingueru batec errihaz beçala eracusten baitçioen erroloia baten marcan bere biçia, hilçeraco Vesperan Çuela haren errethaulan aguer() den beçala

Contempletetan Lorrenaco margarita alençogo duqueça Ceinac bere buruba, bici selari) hiltçat baitçaducan, huntaraco) bere beguien aitçinian çaducala errethaulabat Ceinetan pintaraçy baitçuen bere burua hilla içan baliz beçala Gataboutebatian, ikhusico duçuen beçala haren Errethaulan; devotac imita Caçue Seindu Sandi hauc bere biçiçe Seinduetan, eta orduban Caratesquete jçenez eta obras, devotac.

10. Le paragraphe est dans l'ensemble maladroit, et fautif dans sa partie finale car le pronom relatif ceinac est soit intégré dans une comparative régie par beçala, ce qui est agrammatical, soit associé au verbe duqueçue, ce qui est également agrammatical, puisqu'il n'y a pas d'accord pluriel, et que le verbe n'est pas porteur d'une marque de subordination (bait-).

11. Telle est la forme de la copie manuscrite qui se trouve dans le fonds Urquijo (Bibliothèque de Centre culturel Koldo Mitxelena de Saint-Sébastien). Elle corrige le texte reporté par Vinson dans son édition de 1910 où il propose icharrloez et dans le supplément de sa Bibliographie qui porte iracharloera. Le Diccionario General Vasco indique à l'entrée ixarlo que la seule occurrence rencontrée est celle ici mentionnée, et qu'il pourrait s'agir d'une coquille pour iratxarlo, que donne Harriet en indiquant : Plante qui étymologiquement paraît tenir de la fougère; en tout cas flexible et dont on peut faire des vêtements grossiers. C'est certainement le cas.

Harriet, dans le commentaire du vocable, cite d'Argainaratz en s'appuyant sur un passage de l'ouvrage (qui ne correspond pas au prologue) : Etcuen urrhe, cillarrez bere soin berreguiña. Baiñan bai iratcharloez desertuan eguiña; il traduit : Elle (Marie $<l '>$ Egyptienne) n'avait pas la robe ornée d'or et d'argent, mais bien faite au désert de Etym. ira, fougère, charloa qui ne se trouve pas ailleurs, à moins que ce 
ne soit le même mot que [mot difficilement lisible dans la photocopie dont je dispose, et commençant par ch-] ce qui est peu probable.

Observons que dans ce passage le mot apparaît avec une affriquée après ira-, contrairement à la forme du prologue du manuscrit du fonds Urquijo (iracharlo vs iratcharlo). Dans les deux cas la désinence d'instrumental est au pluriel (-ez), ce qui se comprend dans le cas de la citation rapportée par Harriet puisque le mot rime avec zaharrez, mais tel n'est pas le cas dans le prologue et on attendrait alors l'indéfini. Enfin, notons que la traduction proposée par Harriet est déduite : apparemment il ne connaissait pas ce nom, et il semble en déduire le sens d'après le contexte et une analyse du terme, celle-ci demeurant d'ailleurs inachevée, le second terme du composé n'étant pas clairement identifié.

12. En l'état le texte ici aussi est fautif. La présence de ceinari en tête de la proposition implique une relative à pronom relatif mais la marque de subordination sur le verbe ne saurait être alors - la (suffixe qui, s'il renvoyait à une proposition adjointe modale, serait possible ici, mais qui excluerait alors ceinari).

13. Il s'agit probablement d'une coquille. La copie manuscrite a bien erroloia, ainsi que la version de Vinson du supplément de sa Bibliographie.

14. Linterprétation de la traduction, qui s'éloigne quelque peu de la lettre du texte source, est incertaine. Vinson propose la traduction suivante : Dévots, ce petit bréviaire vous arrive, comme le vôtre, avec le nom" des dévots" à la façon dont vous êtes dévots, mais, afin qu'il vous rende encore plus dévote votre manière d'être dévots, vous l'aurez ainsi qu'il vous présente pour enseignement les vies dévotes de sept princesses saintes, comme vous le verrez dans leur tableaux. (Supplément de sa Bibliographie, p. 557)

15. Je traduis d'après l'interprétation de Harriet, reprise par le Diccionario General Vasco, et qui suppose un composé formé sur ira 'fougère', bien que le second élément du composé soit problématique, cf. note supra). Vinson dans le supplément de sa Bibliographie (p. 557) préfère vêtue de ses cheveux.

16. Vinson interprète vezpera comme signifiant 'vêpre' ici (et non 'veille (d'un jour) '. Outre le sens du texte, l'emploi du singulier dans la déclinaison me parait plutôt favoriser l'autre leçon. La traduction de Vinson de ce passage, qui diffère également de la nôtre sur d'autres points, est la suivante : A Vêpres, sainte Hélène, qui était occupée à contempler l'heure de sa mort; c'est pourquoi elle tenait devant ses yeux un tableau où un ange lui montrait comme du doigt sa vie dans la marque d'une horloge, qu'elle allait mourir à vêpres, comme il paraît dans son tableau. (Vinson, supplément de sa Bibliographie, p. 557)

17. Selon la composition de l'ouvrage, il semblerait que l'avis au lecteur se termine ici, puisque vient ensuite le titre de l'ouvrage. En fait les paragraphes qui suivent et qui précèdent les approbations, sont dans le prolongement de l'avis au lecteur (topos de l'humilité et rappel conventionnel du but édificateur de l'ouvrage).

18. Cette phrase est fautive, la proposition déclarative n'étant pas régie; peut-être le verbe recteur a-til été omis. Je n'ai pu consulter la version originale de l'ouvrage, et j'ignore si le texte de l'édition d'Akesolo la restitue fidèlement. 